\title{
Determinants of Transfer of Training: A Comprehensive Literature Review
}

\author{
Cornelia Tonhäuser*and Laura Büker \\ University of Göttingen, Department of Business Administration, Chair of Business Education \\ with Focus on Educational Management \\ Platz der Göttinger Sieben 5, 37073 Göttingen, Germany
}

Received: 20.04.2016; Accepted: 01.08.2016; Published: 24.08.2016

\begin{abstract}
Investments in training measures can only be considered effective if the transfer of the learned contents to practical situations is continuously successful. In this context the scientific and professional discourse regarding the effectiveness of further education, especially regarding transfer of training, has intensified considerably. This analysis provides a systematic and comprehensive overview of the current state of international empirical research regarding major determinants of transfer of training in the context of formalized further vocational training. Our review of literature differentiates the most important determinants on the organizational level of the characteristics of the work environment, the learning field level of measure-specific characteristics, as well as characteristics of participants on the individual level. Decades of transfer research brings forth a wealth of information regarding determinants which influence the transfer of training. The current analysis systematizes these results and clarifies that research regarding the determinants of the process of transfer of training identifies positive relationships at the three levels. In particular, the question of which determinants positively influence the success of transfer of training is well-studied for the individual level. The article shows that there is still a research deficit concerning the determinants of transfer of training at the learning field and organizational level. There is particular need for research regarding the dimensions of the determinants at the three levels. Finally, in this context this article identifies promising directions for future research.
\end{abstract}

Keywords: Transfer of Training, Training Evaluation, Literature Review, Formal Training, VET, Vocational Education and Training

${ }^{*}$ Corresponding author: cornelia.tonhaeuser@wiwi.uni-goettingen.de

ISSN: 2197-8646

http://www.ijrvet.net 


\section{Determinants of Transfer of Training: A Comprehensive Literature Review Introduction}

The scientific and professional discourse regarding the effectiveness and efficiency of further vocational training, especially regarding transfer of training, has intensified considerably. In the practical reality of further vocational training, the organizational form of formalized and institutionalized training measures determines the off-the-job perception of further education in the relevant organizations' and companies Education Departments (v. Rosenbladt and Bilger, 2008; Schuchmann and Seufert, 2013). Therefore in this article the focus will be directed exclusively to formalized further vocational measures. The reason for this is that, on the one hand, in further education, learning mostly takes place in course or seminar form off-the-job. On the other hand, formally organized learning settings represent the dominant design. In times of intense efficacy debate, the design of further vocational learning processes and their results and effects in the context of an optimal organization and efficient governance of vocational training processes is of great interest. In the context of high further vocational training expenditures by companies, there now exists a high level of cost-awareness and strict result-orientation in vocational and, particularly, in company training measures. The success of investments in further vocational training can be considered from two perspectives. The educational perspective on the one hand focuses primarily on enhancing individual competencies. The economic point of view on the other considers especially to what extent this measure enables the transfer of the learned material from a learning environment to one of practical application in the workplace. This positively influences the working process and employee performance, producing better economic results. There are, however, considerable uncertainties regarding the effectiveness of further vocational training. Especially the efficacy of conventional, formalized training measures in the shape of seminars, classes or training is questioned regularly. Hitherto, in further vocational training, the question of how the transfer of training problem applies both theoretically and practically has been resolved unsatisfactorily (e.g. Hutchins et al., 2010). The main problem of transfer of training is considered to be that formalized training measures often see participants acquire skills which they do or cannot apply appropriately in their workplace. That is, it is assumed that said participants often fail to optimally transfer what they have learned in training measures to their everyday work routine. Expert literature often contains estimates regarding lower transfer rates. Several authors (Baldwin and Ford, 1988; Georgenson, 1982; Kauffeld et al., 2008; Lemke, 1995; Solga, 2005) assume that only $10-20 \%$ of lesson content is applied in the workplace. However, empirical findings of Saks and Belcourt (2006) confirm higher transfer rates. According to this study, immediately after a training, $62 \%$ of training content is applied in the workplace, falling to $44 \%$ after six months and $34 \%$ after a year. Differing results regarding transfer rates can be attributed to modifiable personal and situational determinants. For this reason, an analysis of the determinants of transfer of training is indispensable. They provide evidence of which determinants significantly influence the success of learning transfer, be it positively or negatively. For a deeper understanding of determinants in their dif- 
ferent dimensions, it is necessary to specify them in their facets and partial aspects. The significance of the identification and analysis of determinants and their specifics is emphasized by the results of the SCIL-trend studies (Diesner and Seufert, 2013, 2010; Diesner et al., 2008). These show, that HR managers still consider the transfer-boosting design of training measures as the leading challenge for companies. In this context, the goal of the following analysis is to provide a systematic and comprehensive overview of the current state of international research regarding determinants of transfer of training and their dimensions. Despite a long tradition of transfer research, there is still a dearth of satisfactory explanations concerning determinants and their dimensions which boost or hinder transfer of training. Therefore, we aim to answer the following research questions: RQ1: To what extent has literature already explored empirically confirmed determinants of transfer of training and their dimensions on the individual, learning field and organizational levels in formalized further vocational training measures? RQ2: Which areas provide potential directions for future research? The research objective of this review of literature is to identify relevant determinants and their dimensions which boost or hinder transfer of training and to analyze directions for further research. To answer these research questions, we develop an overall research framework (see Figure $1)$.

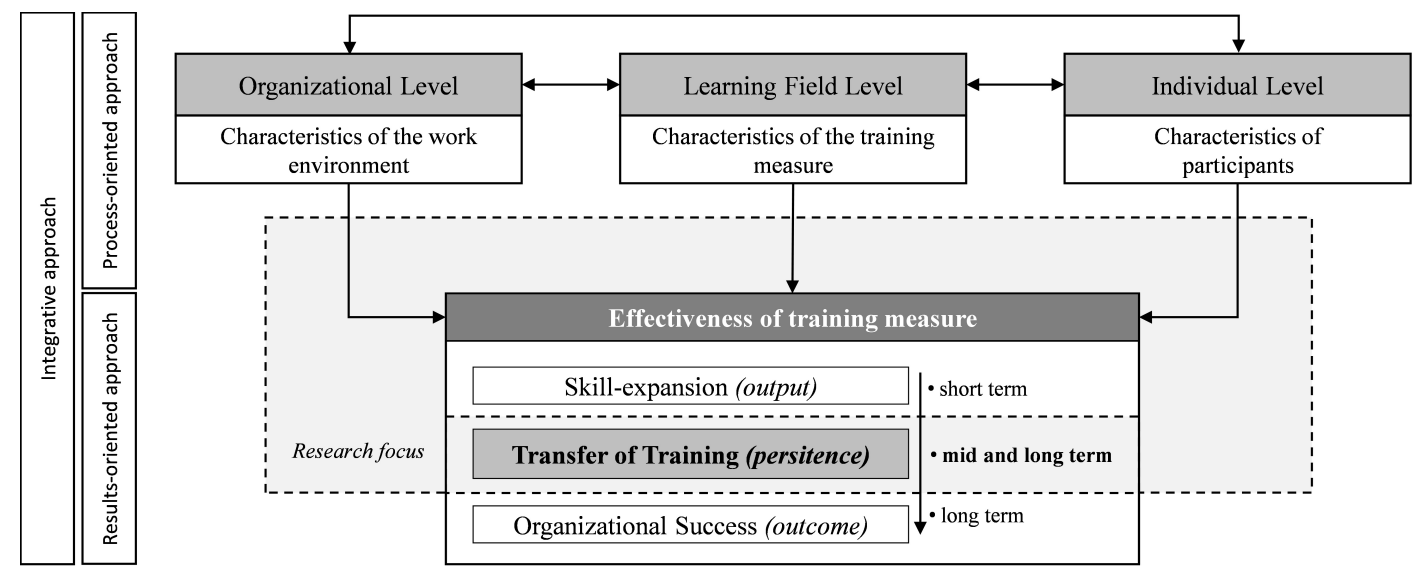

Figure 1: Overall research framework.

As shown in figure 1, a differentiation is made between results- and process-oriented research approaches. Result-oriented approaches focus on the effectiveness of training measures. In doing so, following Kirkpatrick and Kirkpatrick (2006) a further differentiation is made between the steps of skill expansion (output), transfer of training (persistence) and organizational success (outcome). Process-oriented approaches are concerned with the determinants of the effectiveness of a training measure. The determinants can be assigned to the organizational, learning field and individual levels. This differentiation is based on the analysis of central models of transfer of training (see Table 1). The levels are defined as follows: At the organizational level, the determinants 
of the work environment in relation to transfer of training are analyzed. Examples for this are social support, as well as structural and organizational circumstances in the workplace. On the analysis level of the learning field, the determinants of the training measure are examined. Here, the focus is mainly on specific aspects of the training design, such as practical relevance of contents and the didactic-methodological design. On the individual level, the participant is the focus of observation. The influence of further vocational training participant determinants, such as motivational, volitional and personal factors, as well as cognitive abilities, on the transfer of training is examined. The three levels reciprocally influence each other. Our research focus, shaded gray in figure 1, is focused on the direct influence these three levels have on transfer of training. In contrast to previous reviews (e.g., Baldwin et al., 2009; Cheng and Hampson, 2008; Cheng and Ho, 2001; Grossman and Salas, 2011) this current literature review allows a more comprehensive perspective on the current state of research regarding transfer of training determinants in the context of formalized training. Several of the previous literature reviews (e.g., Baldwin et al., 2009; Cheng and Hampson, 2008; Cheng and Ho, 2001; Grossman and Salas, 2011) did not take into account all determinants on the organizational, learning field and individual level, and do not portray the content-related dimensions of these determinants. Next to the determinants, this review has a particular focus on the analysis of the dimensions. Therefore, this literature review systematizes (for the organizational, learning field and individual level) those previous empirical studies, which detect determinants directly influencing the transfer of training on the basis of regression and structural equation analyses. Furthermore, this review includes both studies which examine the direct influences on transfer of training, classified by three levels namely the organizational, learning field and individual level, in the context of educational-psychological and management science oriented empirical transfer research.

\section{Theoretical Background}

\subsection{The Notion of Transfer}

In the relevant literature, the notion of transfer is not used in a uniform way. Generally, both older and newer understandings assume that transfer takes place when something learned in one situation is transferred to another. The understanding of the term 'transfer' differs primarily in whether it is regarded as the application of the learned material in a situation of application (e.g., Lemke, 1995; Solga, 2005) or as the transfer of the learned material to the situation of application (e.g., Rank and Wakenhut, 1998). Baldwin and Ford (1988) also point out the necessity of generalizing the learned material, something which only becomes apparent through the scope of the application in the function field. Newer transfer research also specifies that transfer occurs when a learning process takes place in a certain context (source), such as a systematically planned training measure, and the learner successfully applies the learned material in a second (changed) context (target) such as a (new) task or problem in the field of practice (Mandl et al., 1992). In the context of further vocational training, transfer of training is understood to mean the application and generalization of new knowledge and skills in the workplace, fol- 
lowing Kauffeld, Lorenzo and Weisweiler (2012). But since this paper also considers the pedagogical-psychological aspect of transfer of training, this definition is not precise enough. It is therefore supplemented by the definition of transfer competence, according to Seidel (2012). This places a stronger focus on the individual. According to Seidel (2012), transfer competence is the employee's individual specific disposition. This is a prerequisite for a change in working behavior taking place in situations which are characterized by new and/or changed work tasks. Transfer competence is signified by the work environment in terms of context, and by training in terms of content. On the whole, transfer of training therefore includes the organizational, learning field and individual levels. Furthermore, successful transfer of training is considered to be the mid- and long-term effects of a training measure, the timescale being crucial for the definition of the term continuously successful.

\subsection{Approaches to Evaluating the Efficacy and Transfer of Training of Formalized Further Vocational Training}

The current economic and pedagogical-psychological research regarding the efficacy of further vocational training is shaped by two main research approaches, the resultsoriented and the process-oriented research approaches (Gessler, 2012). The resultsoriented research approach stems from the 1960s (e.g., Alliger et al., 1997; Barba Aragon and Sanz Valle, 2012; Kirkpatrick and Kirkpatrick, 2006; Phillips, 1991; Phillips and Phillips, 2001; Phillips et al., 2001) and focuses exclusively on the sphere of results. This means it focuses on the detection of effects in the sense of (intentional or unintentional) influences on training measures which are observable, measurable and assessable in the short as well as the long term. In the systematic result evaluation of training measures both science and industry fall back mainly on the four-level-evaluation-model of Kirkpatrick and Kirkpatrick (2006). This model suggests conducting an evaluation on the following four levels: During the first level, Reaction, the reactions of training participants regarding their subjective satisfaction with the training measure are recorded directly after its conclusion. During the second level, Learning, learning success is measured in terms of the scope of changes in attitude, knowledge, and skills of the participants. The next level, Behavior, examines the extent to which the behavior of participants has been altered, thereby evaluating the transfer of training. Finally, at the Results level, all effects a measure has on company success are to be included in the evaluation (Kirkpatrick and Kirkpatrick, 2006). The evaluation of results serves to examine the effectiveness of training measures and comprises the assessment of both educational and economic effects of educational processes directly after a training measures conclusion, on three possibly levels of effectiveness:

- Results regarding learning success in the sense of skill-expansion (output), which are measurable in the short term,

- Transfer of training success, that means, mid and long term effects on employee performance (persistence), 
- Long term economic effects concerning the organizations success, for example, the Return on Investment (ROI) of a training measure, sinking rates of errors and complaints, cost-reductions or revenue increases which have been achieved (outcome).

Numerous current studies take the uniform position (e.g., Kabst et al., 2009; Saks and Burke, 2012; Zurwehme, 2008), companies primarily examine the reactions of participants as well as the gains they have made through learning. However, transfer of training and the effects training measures have on a companys success are rarely examined. The relationships and connections between the four evaluation levels described above, assumed by Kirkpatrick and Kirkpatrick (2006) in their model, have not been unambiguously empirically confirmed. Several papers (Alliger et al., 1997; Barba Aragon and Sanz Valle, 2012; Festner, 2012; Liebermann and Hoffmann, 2008; Lim and Morris, 2006; Piezzi, 2002) have found no relationship between the participants satisfaction with a training measure and/or knowledge acquisition as well as transfer of training success. The paper of Saks and Burke (2012) on the other hand, confirmed a link between the evaluation levels of a training measure in a company and transfer of training. A further study conducted by Colquitt, LePine, and Noe (2000) was also able to substantiate a significant positive effect of transfer of training on work performance. On the whole, however, the findings have been very heterogeneous. Furthermore, the results-oriented research approach neglects not just the input (i.e., the training measure and its methodologicaldidactic configuration), but also the process perspective (i.e., the process of transfer of training and its positive support). Neither causes nor the determinants which boost or hinder transfer of training are examined (Bates et al., 2000; Gessler, 2012; Kauffeld et al., 2008). The question of how training can be configured and designed in a way that boosts transfer of training remains disregarded by results-oriented approaches and studies, too (Gessler, 2012). In results-oriented research regarding the efficacy of further vocational training which focuses primarily on learning effectiveness, the meta-analysis of Arthur, Bennett, Edens, and Bell (2003) must be highlighted. This investigation into the learning effectiveness of training measures suggests an average effectiveness of $d=.60$. This indicates that formalized training measures significantly contribute to the development of competencies. Further studies (e.g., Kauffeld and Grote, 2000) also point out that training substantially contributes to the development of employee competencies. These gains in competence and learning, however, do not by themselves tell us anything about the extent to which the newly acquired competencies are employed in the functional field of the workplace. The process-oriented research approaches developed in the late 1980s (e.g., Baldwin and Ford, 1988; Bates et al., 2000; Holton et al., 2000) are more focused on the sphere of the processes in the context of their nature. This means they focus on the implementation and micro-didactic design of the training measures as well as the transfer support (Gessler, 2012). Results- and process-oriented research approaches therefore intend to gather either all possible results, or at least all exogenous determinants (Gessler, 2012). Within the framework of process-oriented research concerning the efficacy of further vocational training, there now exist numerous research papers. The 
main focal point amongst these are research papers which model and examine transfer of training and the interaction of different determinants (e.g., Baldwin and Ford, 1988; Cannon-Bowers et al., 1995; Colquitt et al., 2000; Holton et al., 2000; Noe, 1986; Piezzi, 2002; Rank and Wakenhut, 1998; Seidel, 2012). In this review of literature we systematize the research results to the determinants for the transfer of learning, with the help of the important transfer models presented here (see Table 1), into three main categories:

- Organizational level of the characteristics of the work environment,

- Learning field level of the characteristics of the training measure,

- Individual level of the characteristics of participants.

Table 1 provides an overview of the main determinants already modeled in important transfer models, and differentiated between by these three levels of characteristics.

Table 1: Overview of Modeled Transfer of Training Determinants in Important Transfer of Training Models

Levels of

characteristics Determinants in Transfer of Training Models

Organizational Social support through superiors and colleagues

level

(Baldwin and Ford, 1988; Holton et al., 2000; Noe, 1986)

(characteristics of Possibility of application in the field of function

the work

(Baldwin and Ford, 1988; Holton et al., 2000; Noe, 1986)

environment)

Positive or negative consequences of non-application

(Holton et al., 2000)

Reconstruction and re-contextualization of the learning activity

(Piezzi, 2002)

Social climate within the field of function (Noe, 1986)

and transfer climate (Holton et al., 2000)

Design of the working activity (Piezzi, 2002):

- work tasks and autonomy at work (Noe, 1986)

- working and transfer conditions (Piezzi, 2002)

Organizational and situational characteristics (Cannon-Bowers

et al., 1995):

- organizational structure (Rank and Wakenhut, 1998)

- incentive schemes (Piezzi, 2002) 


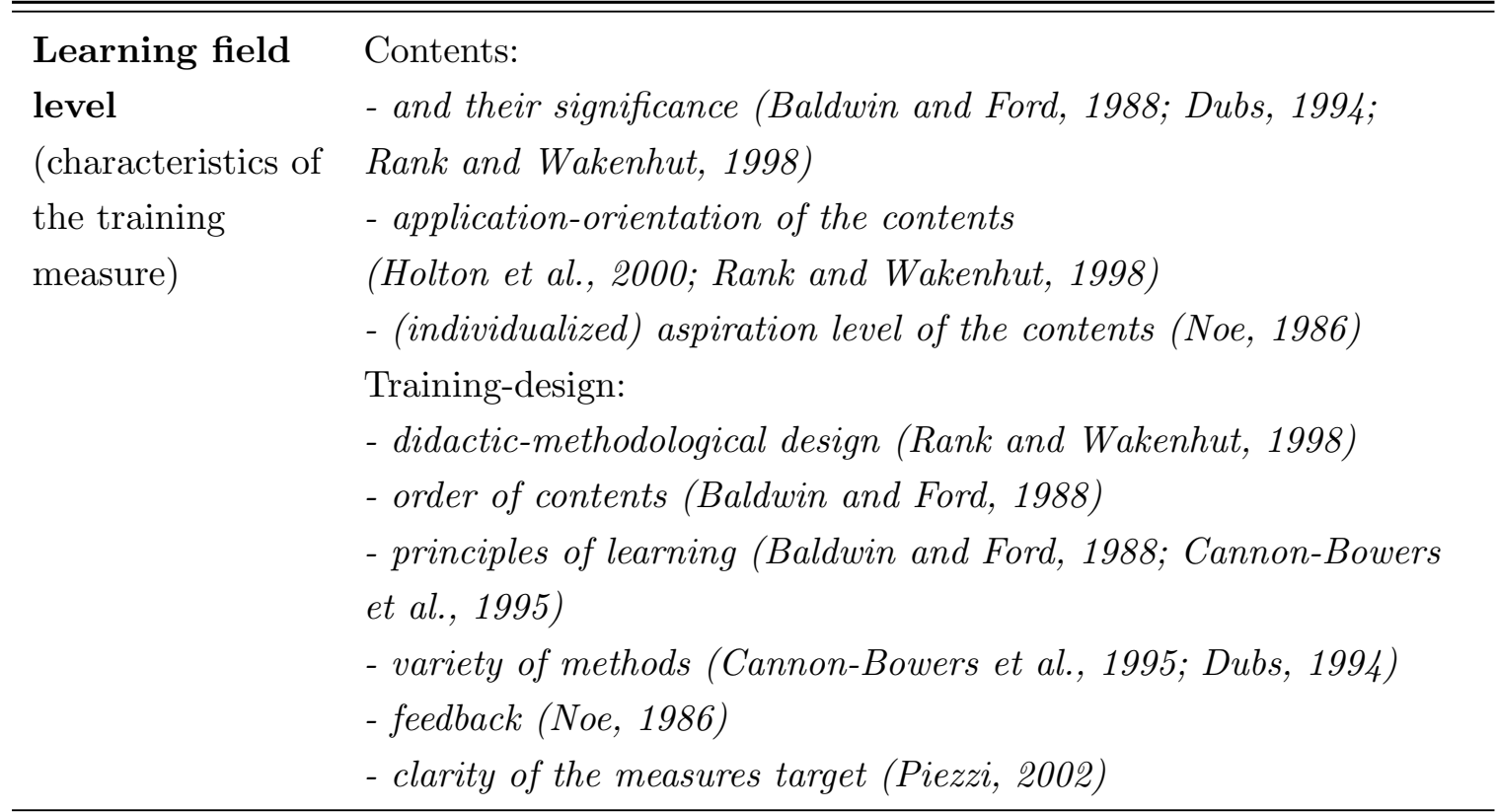

Individual level Cognitive skills (Noe, 1986; Seidel, 2012)

(characteristics of Prior knowledge (Piezzi, 2002)

participants) Individual transfer capacity (Holton et al., 2000)

Motivation:

- learning motivation (Noe, 1986)

- training motivation (Cannon-Bowers et al., 1995; Colquitt et al., 2000)

- transfer motivation (Baldwin and Ford, 1988; Holton et al., 2000; Noe, 1986; Piezzi, 2002; Seidel, 2012)

Volition:

- conviction of self-efficacy (Cannon-Bowers et al., 1995; Colquitt

et al., 2000; Noe, 1986; Seidel, 2012)

- controlling convictions (Noe, 1986; Seidel, 2012)

- self-control (Piezzi, 2002; Seidel, 2012)

Personal factors:

- personality traits (Baldwin and Ford, 1988; Colquitt et al., 2000; Piezzi, 2002; Seidel, 2012)

- (work-related) attitudes (Cannon-Bowers et al., 1995; Colquitt et al., 2000; Noe, 1986; Piezzi, 2002; Rank and Wakenhut, 1998 - expectations (Noe, 1986; Rank and Wakenhut, 1998; Seidel, 2012) 
As Table 1 elucidates, the analyzed key transfer models are uniform in identifying and differentiating between the main characteristic levels of organizational, learning field and individual characteristics in order to explain transfer of training and the interaction of its determinants. Hereinafter, a systematic and comprehensive overview of the currently existing essential empirical findings regarding transfer of training determinants differentiated by organizational, learning field and individual levels is provided.

\section{Method}

To identify the extent to which the body of research literature has already explored the determinants of transfer of training, an extensive, topic-based literature review was conducted following the principles of Webster and Watson (2002). In order to adequately explore the literature base for identifying and examining empirical studies in regard to most important transfer of training determinants, we included the following databases: PSYNDEX, PsycINFO and Business Source Complete. The first two data bases were particularly useful for identifying empirical studies in the context of educational-psychological transfer research. The last data base was added to enable the identification of empirical studies primarily in the field of management science oriented transfer research. These databases cover all important journals in transfer research. To provide a comprehensive overview of the concept of transfer of training in transfer research the following keywords were used: transfer of training, training transfer, transfer of learning, learning transfer. These keywords are, on the whole, used synonymously in research. The concepts transfer of learning and learning transfer, however, have a strong pedagogical connotation, and are therefore frequently used in the context of educationally-psychologically oriented empirical transfer research. The terms transfer of training and training transfer, on the other hand, are discussed under the organizational aspect. They are therefore primarily used in management science oriented empirical transfer research. As previously explained, in this review, the definitions of Kauffeld et al. (2012) are therefore supplemented by the construct of individual transfer competence according to Seidel (2012). Hence, the organizational, learning field and indiviual levels are all incorporated in the construct of transfer of training. To make a comprehensive review of literature possible, all constructs were considered with their respective connotations. Furthermore, the analysis is restricted to the time span from 1990 until 2015, since publications until 1990 have already been examined by Badwin and Ford (1988). Additionally, the volume of publications on this topic rapidly increased over the last two decades (Grossman and Salas, 2011). As a result, several literature reviews exist (e.g., Baldwin et al., 2009; Burke and Hutchins, 2007; Cheng and Hampson, 2008; Cheng and Ho, 2001; Grossman and Salas, 2011; Zu Knyphausen-Aufse et al., 2009). However, these studies do not take into account all determinants on the organizational level, the learning field level and the individual level, and do not portray recent findings in particular. In order to ensure research rigor, only empirical findings from studies published in academic journals with a double-blind review process are included in this analysis. 
Furthermore, this literature review systematizes previous empirical studies, which provide statistical results on the basis of regression and structural equation analyses. The focus of this analysis is on empirical studies examining direct influences on transfer of training. The collection of data followed a multistage process. In the first step, the consultation of databases was conducted. However, since we used multiple databases and similar search strings, a number of results appeared more than once. Such identical results were removed. In the second step, the titles and abstracts of the remaining articles were analyzed to eliminate irrelevant results, resulting in the exclusion of articles from further investigation for the following main reasons: First, publications that do not deal with the concept of transfer of training in the context of professional training or further educational training have been excluded from the review. For example, studies in the context of knowledge and skill transfer in universities and schools (e.g., Cheng, 2000; Pham et al., 2013). Second, since the study focuses on transfer of training as a process-oriented approach, studies that exclusively focus on the results-oriented approach, such as Barba Aragon and Sanz Valle (2012), were excluded. Third, all studies which do not focus on formal learning were excluded, such as Lau and McLean (2013) who studied the transfer of training of an outdoor management program. Lastly, the analysis is restricted to quantitative studies. Therefore studies using qualitative research methods (e.g., Clarke, 2002; Ellström and Ellström 2014; Lim and Johnson, 2002) have also been eliminated since they do not allow for a comparison of results. In the next step, the list of references of the articles was used to conduct a backward search, i.e., the references of articles found by the search were searched for further relevant articles, following the same procedure, which led to more publications. Finally, the lists of references of existing literature reviews (e.g., Baldwin et al., 2009; Cheng and Hampson, 2008; Cheng and Ho, 2001; Grossman and Salas, 2011) were analyzed. In the end 79 publications, including five meta-analyses, were identified for further investigation.

\section{Results}

\subsection{Organizational Level of the Characteristics of the Work Environment}

The term transfer climate (Rouiller and Goldstein, 1993) has become widely established for examinations of the impact that the working environment has on transfer of training. According to Rouiller and Goldstein (1993), the transfer climate consists of situational determinants such as social assistance and support through superiors, colleagues and subordinates in aid of the transfer process, as well as task-related and structural circumstances related to the workplace and work tasks. Furthermore, Roullier and Goldstein (1993) subsume consequences such as positive or negative feedback and sanction under transfer climate. The authors have examined what influence the transfer climate and learning success have on transfer success, and reached the conclusion that in the examined training measure, a combination of learning success and transfer climate explained $54 \%$ of the variation in transfer success (Rouiller and Goldstein, 1993). The most important institutional determinants which positively influence the transfer process have 
been identified by empirical transfer research as being characteristics of social support on the one hand, and structural and organizational circumstances in the workplace on the other.

Social Support. The most important factor of the transfer climate within the organizational level of work environment is social support (Grossman and Salas, 2011), which has also been the most frequent object of examinations concerning transfer of training. A significant positive influence of support by colleagues on transfer success has been confirmed by several studies (Bates et al., 2000; Cromwell and Kolb, 2004; Facteau et al., 1995; Festner, 2012; Hinrichs, 2014; Martin, 2010; Ng and Ahm, 2011; Ng, 2013). There are different research findings in regard to support by superiors. Some authors do not find support by superiors to have a significant (Chiaburu and Marinova, 2005; Bates et al., 2000; Homklin et al., 2014; Ng, 2013; Velada et al., 2007), or even a significantly negative influence on transfer of training (Facteau et al., 1995) in their studies. The majority of studies, however, indicate a significant positive influence of this variable on transfer of training (e.g., Cromwell and Kolb, 2004; Festner, 2012; Lee et al., 2014; Ng and Ahm, 2011; Scaduto et al., 2008). Hinrichs (2014) differentiates between attituderelated and action-related support from the superior. While the action-related transfer support (the extend to which the superior discusses concrete possibilities of application) could be identified as a predictor of transfer of training, the attitude-related support (the extend to which the superior is interested in the application of the newly learned) does not have a significant direct influence on transfer of training. Furthermore, Blume et al. (2010) determine support by superiors to have a greater impact than support by colleagues on transfer of training in their meta-analysis, and confirm that the support of superiors is one of the strongest predictors for transfer of training. This highlights a further need for research regarding the effect support from superiors has within the process of transfer, demanded, amongst others by Burke and Hutchins (2007) and Cheng and Hampson (2008). Bhatti et al. (2013) speak out in favor of examining the different dimensions of social support through both superiors and colleagues more closely in future empirical studies. The best-examined of these has been the use of feedback. It has been substantiated that receiving feedback has a significant positive impact on transfer of training (e.g., Goodman et al., 2011; Van den Bossche et al., 2010; Velada et al., 2007). The study conducted by Van den Bossche et al. (2010) also demonstrated that feedback subjectively perceived to be helpful has a positive influence on transfer of training. The frequency of feedback, however, has a significant negative impact on transfer of training.

Structural and organizational circumstances in the workplace. The current state of empirical research regarding the influence of certain structural circumstances in the workplace can be systematized into three dimensions: Opportunities to implement the learned material, commitment, and organizational and learning cultures. The construct implementation opportunity describes the extent to which the participants are provided with all resources necessary to implement the learned material following a training session (Bates et al., 2000). Here, studies concurrently demonstrate that posi- 
tive transfer can only take place in a limited fashion, if at all, if there is no opportunity to implement the training contents at work (e.g., Cromwell and Kolb, 2004; Ford et al., 1992; Seidel, 2012). Renta-Davids et al. (2014) have also substantiated that the variability of work tasks has a significant positive influence on transfer of training. The variability of work tasks describes the degree to which a job entails a variety of different activities: activities changing over time, different tasks to do (Renta-Davids et al., 2014, p. 735). The authors explain that if training is related to work and work activities are diverse, then participants would have more opportunities to implement the training contents. In regard to the examination of the transfer of training determinant commitment, that is, the extent to which a person identifies with the company they work for, the findings on hand are inconsistent. While numerous studies have examined commitment as a predictor for learning and transfer motivation, its direct influence on the evaluation level of transfer of training has been seldom analyzed. Cheng (2000) substantiated a significant negative impact of this variable on learning motivation, whereas other authors (Facteau et al., 1995; Kontoghiorghes, 2002; 2004; Lee et al., 2014; Tannenbaum et al., 1991; Tracey et al., 2001) have confirmed a positive relationship between commitment and learning motivation. A significant positive effect of commitment on perceived transfer of training has also been verified (Facteau et al., 1995; Kontoghiorghes, 2004). Furthermore, Pidd (2004) has determined that the influence of social support on transfer of training is also influenced by the company-identification of the participants. Individual studies have also examined the influence that organizational and/or learning cultures within a company have on transfer of training. In her study, Simosi (2012) differentiates, in accordance with Cooke and Rousseaus (1988) framework of organizational cultures, between humanistic and achievement cultures. Humanistic organizations are marked by being person-oriented, which means that members of an organization support and help each other. The focus of members of an organization is teamwork, involvement and empowerment. An achievement culture orientation, on the other hand, is marked by standards of excellence. Members of an organization are expected to set themselves targets, and to achieve these. The author substantiates that both have a significant positive influence on transfer of training. This also holds true for organizations in which employees are intimately integrated into the company and have a flat hierarchy (Kontoghiorghes, 2001). Furthermore, Kontoghiorghes (2004) demonstrates that both risk taking an innovation driven culture as well as quality driven cultures in organizations positively influence transfer of training. In their study, Lim and Morris (2006) have substantiated a significant positive influence of the construct organizational climate on transfer of training. According to Lim and Morris (2006) this construct contains organizational determinants such as reactions to change, learning support, opportunities for transfer, and feedback from colleagues. Moreover, Martin (2010) has examined the working climate, specified by the author as the managements attitude towards the training program. He was able to demonstrate that participants whose management has a positive attitude towards the training program achieve a higher rate of transfer of training (Martin, 2010). Furthermore, the study conducted by Egan et al. (2004) confirmed that organizations with a learning culture, measured by the standards of the Dimensions of Learning Organization Questionnaire (DLOQ; (Marsick and Watkins, 2003; Watkins 
and Marsick, 1993), have a significant positive influence on the job satisfaction, transfer motivation and transfer intention of the participants. Piezzi (2002) examined the integration of training into company strategy. The author was able to confirm a significant positive impact of this variable on transfer motivation (Piezzi, 2002). In conclusion, social support is the most examined determinant in the context of transfer of training on the organizational level. However, there is a need for further research regarding the dimensions of social support. Studies that examine structural and organizational circumstances in the context of transfer of training are rather limited in terms of both scope and focus. As a result, research failed to respond to the demand (e.g., Egan et al., 2004; Piezzi, 2002) for further studies on the proposed relationship between the distinct determinants, including opportunities to implement the learned material, commitment, and organizational and learning cultures, and transfer of training. This is particularly true for organizational and learning cultures as antecedents of transfer of training.

\subsection{Learning Field Level of the Characteristics of the Training Measure}

The statistically significant measure-specific determinants of the transfer of training process that have been identified by empirical research and are to be subsumed on the learning field level, can be systematized according to transfer-boosting measures before, during, and after a training measure following Rank and Wakenhuts (1998) transfer of training model. Saks and Bulcourt (2006) have already determined that measures before, during and after training all have a significant influence on transfer of training.

Pre-training measures. As part of an intervention study, Weissbein, Huang, Ford, and Schmidt (2011) investigated the use of videos in influencing the attribution-style of participants as a transfer-boosting pre-training measure. The video showed that negotiating skills can be improved through ones own effort and the use of negotiating strategies which would be subject of the subsequent seminar. Said films shown before the training measure were also intended to boost the learning motivation of participants. The study was able to substantiate that pre-training use of the videos had a strong positive influence on controlling convictions, which in turn had a positive impact on learning motivation. A direct, significant positive impact of these specific intervention measures on transfer of training was also empirically confirmed (Weissbein et al., 2011).

Measures during training. Seidel (2012) substantiated in her study, that high practical relevance of training, for example by including real-world examples, practice-oriented tasks or case studies, has a significant influence on transfer of training. The Bates et al. (2000) study has demonstrated that the contents of a training measure should correspond to the demands of the working environment in order to foster a positive transfer of training. Furthermore, the study of Hinrichs (2014) showed that transfer orientation of the training, which reflects the extent to which the training resembles the real work situation, has a positive influence on transfer of training. Van der Locht et al. (2013) examined the role of identical elements between the learning situation and the 
implementation situation as part of the process of transfer of training, based on the theory of identical elements according to Thorndike and Woodworth (1901). The study was able to substantiate that similarities between training and everyday work situations has a positive impact on both transfer motivation and transfer of training. Contrary to expectations, however, the findings of Festner (2012) indicate that a learners activeness during a seminar, measured in high participation rates during discussions and self-sufficient problem-solving, has no positive impact on subjective transfer estimates or transfer of training. This is largely consistent with findings from Hinrichs (2014). Hinrichs (2014) also did not find training and learning conditions like the methods, the situatedness of learning environment and the competence support by the trainers as predictors for transfer of training. This contradicts the findings of Weisweiler (2008), who substantiated in an experimental control-group design that training designs with a constructivist orientation which follow the principle of situated learning lead to a higher transfer performance amongst participants. Several studies have examined the connection between the setting of learning goals as an element of training and transfer of training. These have shown the setting of learning goals to have a significant positive impact on transfer of training (Blume et al., 2010; Johnson et al., 2012; Richman-Hirsch, 2001; Werner et al., 1994). Blume et al. (2010), in their meta-analysis, were only able to ascribe a moderate influence on transfer of training to the use of the goal-setting approach. Lee and Pucel (1998) have also demonstrated that learning goals subjectively perceived as more important resulted in a higher rate of transfer of training. In addition, Brown (2005) differentiated between close and remote learning goals, and in the process determined that close learning goals result in a significantly higher rate of transfer of training in comparison to remote goals. A number of further studies have focused on the effects specialized error management has on the process of transfer of training. Error management promotes the transfer of training by allowing trainees to anticipate potential issues, providing them with knowledge of how to handle such problems, and highlighting the negative outcomes that can occur if training is not transferred (Grossman and Salas, 2011, p. 107). Gully, Payne, Koles, and Whiteman (2002) have examined the effectiveness of error-management-training. This revealed that learners who are of greater cognitive ability and more open achieve better results on the evaluation levels of learning and transfer of training. An experimental intervention study conducted by Heimbeck, Frese, Sonnentag, and Keith (2003) confirmed that participants who have received explicit instructions concerning error management generate a greater close and broad transfer than participants who were not subject to this intervention. Keith and Frese (2008) in their meta-analysis also reach the conclusion that error-managementtraining leads to better training results than training methods which offer no support in case of errors. The authors do, however, point out that there is a dearth of studies concerned with the aspect of error-management, which also examine the implementation of the learned material in the workplace after a set amount of time has passed (Keith and Frese, 2008). Past studies of the impact of error-management restrict themselves to the measurement of task completion directly after the training, so that the transfer of training itself, and its persistence, have not yet been examined, resulting in a current need for further research. There is a comprehensive body of research regarding the ex- 
amination of training measure effectiveness and behavior modeling (Behavior Modeling Training [BMT]), which Taylor et al. (2005) have summarized in a meta-analysis. The meta-analysis substantiates that the biggest effects could be achieved on the level of learning, but that BMT also had a positive influence on transfer of training. In regard to the transfer of training effect, the meta-analysis also confirmed that it is at its greatest if learners are provided with positive and negative models. The transfer of training effect is also boosted if tasks contain scenarios developed by the participants themselves, specific learning goals are formulated, superiors participate in training, and rewards and sanctions are part of the working environment (Taylor et al., 2005).

Post-training measures. Research concerning the use of the so-called relapse prevention strategy following a training measure constitutes another focal point. The goal of this strategy adapted from Marx (1982) is to prevent a relapse into old patterns of behavior amongst participants after a training session, and thereby ease the transfer of training contents. It does so by addressing the transfer problem after the seminar, and providing participants with information regarding potentially hazardous situations which may prevent implementation of the learned material. Raising awareness of the potential for relapse intends to accelerate the transfer of contents. Furthermore, Tziner et al. (1991) demonstrated that as well as significantly higher rates of learning success in comparison to the control group, this intervention also increased transfer of training, because a stronger implementation of transfer strategies took place. Noe, Sears, and Fullenkamp (1990), too, substantiated a high training efficacy for this specific intervention in comparison to a control group. Further studies concerning relapse prevention strategy (e.g., Burke and Baldwin, 1999; Burke, 1997; Gaudine and Saks, 2004) were unable to substantiate significant effects on transfer of training. In the context of this heterogeneous state of research, further research concerning the efficacy of post-training intervention measures is necessary. On the whole, there is still a considerable need for research regarding field-of-learning-specific determinants which positively influence the process of transfer of training (Hutchins and Burke, 2007; Van der Locht et al., 2013). The majority of determinants during and after a training session considered to be transfer-boosting in current models of transfer of training (cf. Table 1) has been scarcely examined in terms of their impact on the process of transfer of training. In regard to the methodological-didactic design of training measures, the impact of method variability, transfer tasks, structure and cognitively activating contents on transfer of training remains almost entirely unexplained. It has already been stated by Burke and Hutchins (2007) that the demand for a more detailed examination of training design as a key influencing factor on transfer of training has only been partially met.

\subsection{Individual Level of the Characteristics of Participants}

The major statistically significant individual determinants of the learning process identified by empirical research at the individual level are learning, training and transfer motivation, cognitive skills, the volitional dimensions conviction of self-efficacy and controlling convictions, personal characteristics, the expected utility as well the intended 
individual goal intention, which is associated with the participation of the training measure.

Learning, training and transfer motivation. Transfer research differentiates between learning, training and transfer motivation. Learning motivation can be defined as a specific desire of the trainee to learn the content of the training program (Noe, 1986, p. 743). Training motivation refers to the intensity of ones commitment to performing in learning situations (Tannenbaum and Yukl, 1992). However, it does become apparent that these terms are not always used precisely and distinctly in existing studies. A number of them use the terms learning and training motivation synonymously, which means a clear differentiation also becomes impossible at times in their analysis, below. According to Noe (1986), transfer motivation can be defined as the motivation of the participants to apply their newly acquired competencies during their everyday work routine. There is empirical evidence for a link between training/learning and transfer motivation (e.g., Chiaburu and Lindsay, 2008; Kontoghiorghes, 2002, 2004; Rowold, 2007). That both learning and transfer motivation can have a significant, positive impact on transfer has been confirmed in numerous studies (Axtell et al., 1997; Bhatti et al., 2013; Chiaburu and Lindsay, 2008; Chiaburu et al., 2010; Facteau et al., 1995; Grohmann et al., 2014; Hinrichs, 2014; Kontoghiorges, 2004; Lee et al., 2014; Liebermann and Hoffmann, 2008; Quiones, 1995; Scaduto, Lindsay and Chiaburu, 2008; Tziner et al., 2007; Van den Bossche et al.,, 2010; Van der Locht et al., 2013). Naquin and Holton (2002) developed the construct Motivation to improve work through learning (MTWIL), which lays claim to covering both training and transfer motivation. The authors examined the predictors of this construct and found that MTWIL is explained by positive affectivity, commitment and extraversion. Other papers have examined which variables influence training and transfer motivation. Some confirm the significant influence of self-efficacy expectations (e.g., Colquitt et al., 2000; Lee et al., 2014; Machin and Fogarty, 2004; Quiñones, 1995), personality traits (e.g., Naquin and Holton, 2002; Rowold, 2007) and work environment variables (Chiaburu et al., 2010; Facteau et al., 1995; Kontoghiorghes, 2002; Lee et al., 2014; Liebermann and Hoffmann, 2008; Seyler et al., 1998) on training and/or transfer motivation. Furthermore, several studies were able to establish that the transfer motivation of the learner serves as a mediator variable between the different input variables and transfer of training. For example, transfer motivation mediates the statistical link between different determinants of transfer (willingness of the learner, support from colleagues and superiors, instrumentality) and transfer of training (Bhatti et al., 2013), the training characteristics (perceived importance of the content and transfer design) and transfer of training (Grohmann et al., 2014) as well as communication between superiors and participants and transfer of training (Scaduto et al., 2008). Findings in regard to transfer motivation as a mediator variable between the variables of learning motivation and transfer of training vary. Unlike Van der Locht et al. (2013), Lee et al. (2014) were able to substantiate that transfer motivation is not a mediator variable between learning motivation and transfer of training. Regarding sources of motivation, both intrinsic and extrinsic determinants which influence the transfer process can be 
identified. However, the studies reflect an inconsistent body of evidence relating to sources of motivation. For example, Facteau et al. (1995), in concurrence with Kontoghiorghes (2001) and Piezzi (2002), determined that intrinsic factors have a greater influence on training motivation than extrinsic factors. The meta-analysis of Taylor, Russ-Eft, and Chan (2005), on the other hand, shows better transfer results when the participant was motivated extrinsically. Gegenfurtner, Veermans, and Vauras (2013) has examined the multidimensionality of transfer motivation and statistically substantiated the distinction between two dimensions of extrinsic transfer motivation, namely autonomous and controlled transfer motivation, as well as transfer intention, by means of factor analyses. Autonomous motivation to transfer can be defined as an internalized desire to transfer learning that is initiated and governed by the self (i.e., regulated by identification or by integration with ones values) (Gegenfurtner et al., 2009, p. 126). The difference to intrinsic motivation is that, although both have an internal locus of causality, autonomous motivation is purpose-oriented and leans towards certain consequences. Controlled motivation, on the other hand, can be described as a desire to transfer learning that is not initiated and governed by the self (i.e., regulated by external rewards or sanctions) (Gegenfurtner et al., 2009, p. 126). The division into autonomous and controlled transfer motivation is justified by the highly specific nature of work environments. It was possible to identify transfer intention as the mediator between the autonomous and controlled transfer motivations and the trainings outcome variables. Furthermore, it became apparent that autonomous transfer motivation has a stronger influence on transfer intention than controlled transfer motivation (Gegenfurtner et al., 2013). Renta-Davids, Jiménez-González, Fandos-Garrido, and González-Soto (2014) differentiate between work-oriented and learning-oriented motivation in their study. The authors were able to prove that work-oriented motivation had a positive influence on transfer of training in their model. Learning-oriented motivation also serves as a mediator variable between the relevance of the transfer of training (Renta-Davids et al., 2014). On the basis of the existing body of evidence, there is a consensus that the learning, training and transfer motivation is to be regarded as a key concept (Bhatti et al., 2013; Egan et al., 2004; Hasselhorn and Mähler, 2000) within transfer research. However, despite there being growing evidence of the positive relationship between transfer motivation and transfer of training, the body of literature is still too narrow to draw a comprehensive picture. In particular, both the mediating role of transfer motivation as well as the different sources of motivation are still under-explored. As a result, one must concur with Gegenfurtner et al. (2009) that further research is required.

Cognitive skills. Numerous older studies have proven that people with greater cognitive ability undergo the learning process of formalized vocational training measures more successfully (e.g., Carter, 2002; Colquitt et al., 2000; Ree and Earles, 1991). Many of these older studies, however, did not examine to what extent cognitive ability also influences transfer of training. The direct influence of learners cognitive abilities on the process of transfer of training has been examined in numerous studies. Bates and Holton (2004), for example, examined to what extent training participants with different levels 
of workplace-related reading and writing skills differ in regard to their transfer of material learned during the training measure to the workplace. The results indicate that significant differences in these skills play a substantial role within the transfer process. Reading and writing skills boost transfer motivation and contribute to the effectiveness of training. Blume et al. (2010), demonstrated in a meta-analysis that of all known variables, cognitive ability correlates the most strongly with transfer of training, even if the causality of the link is merely moderate. Lee et al. (2014) examined the influence of work performance before training on the relationship between variables of the work environment and variables of the transfer process (learning motivation, transfer motivation and transfer of training). The authors therefore define work performance as an input variable of the transfer of training process. In doing so, they differentiate between participants with high and low work performance, and it turns out that the two groups differ significantly with regard to the relationships within the transfer of training process. Only in the group of low-work-performance participants does learning motivations have a significant, positive influence on transfer of training. In the group of high-workperformance participants, on the other hand, support from superiors was proven to have a direct influence on transfer of training. So far, few studies indicate a tendency towards a positive relationship between cognitive skills and transfer of training. However, as this is a highly complex issue, which has not been examined in detail, ambiguity remains concerning the different diemensions of cognitive abilities in the transfer process. For example, future studies should examine not just cognitive abilities, but also the hitherto neglected influence of prior knowledge the participants have, to make the measurement of the transfer effects of a training measure as accurate and reliable as possible.

Volition. Volitional determinants, such as convictions of self-efficacy, controlling convictions and self-control, describe the conscious and deliberate conversion of individual goals and motives into results by purposeful action. The self-regulation processes linked to this require an individual to overcome barriers to action through volition. The dimensions of the determinant of volition in regard to its influence on transfer of training are described hereafter. According to Bandura (1982), expectations of self-efficacy can be defined as the opinion or conviction of a person that, due to their personal abilities, they can successfully accomplish a certain task or action. On the whole, the body of evidence produced by research in regard to these individual determinants of transfer of training is consistent (Grossman and Salas, 2011). It is empirically evident, that expectations of self-efficacy are both a significant positive predictor for transfer of training (Chiaburu et al., 2010; Colquitt et al., 2000; Ford et al., 1998; Holladay and Quiñones, 2003; Mathieu et al., 1993; Simosi, 2012; Tziner et al., 2007; Velada et al., 2007), as well as for learning and transfer motivation (Chiaburu and Lindsay, 2008; Chiaburu and Marinova, 2005; Colquitt et al., 2000; Lee et al., 2014). The meta-analysis of Blume at al. (2010) also confirms the positive relationship between expectations of self-efficacy and transfer of training. Locus of control is the starting point of Noes (1986) model of motivational factors which influence training effectiveness. This construct refers to the extent to which a person believes that the occurrence of an event is dependent on their own behavior, that 
is, controlling convictions are an individuals internal and external attribution of their work results to themselves. Some studies (Cheng, 2000; Noe and Schmitt, 1986; Tziner and Falbe, 1993) demonstrate no significant influence of controlling convictions on the transfer process. Tziner, Haccoun, and Kadish (1991), on the other hand, demonstrate that controlling convictions have a significant positive effect on transfer of training. The meta-analysis of Colquitt et al. (2000), too, confirms these findings on all four levels of evaluation according to Kirkpatrick and Kirkpatrick (2006), and also show that internal controlling convictions have a stronger effect of transfer than external ones. Another meta-analysis (Blume et al., 2010), however, substantiates a small negative correlation between controlling conviction variables and transfer of training. In sum, there are only studies evaluating the relationship between controlling convictions and transfer of training. Evidence reported thus far is contradictory, since the direction of effects varies. Hence, empirical studies do not offer consistent results and are limited in both scope and detail. In particular, studies fail to examine the differentiation between internal and external controlling convictions. Furthermore, future studies should also include the influence of self-control, that is the internal control of ones own actions.

Personality traits. Different authors (Blume et al., 2010; Colquitt and Simmering, 1998; Hinrichs, 2014; Machin and Fogarty, 2004; Rowold, 2007; Webster and Martocchio, 1993) examine the relationship between dimensions of the Big Five main dimensions of personality, namely openness to experience, conscientiousness, extraversion, agreeableness and neuroticism (Costa and McCrae, 1995), and the process of transfer on the respectively selected levels of evaluation according to Kirkpatrick and Kirkpatrick (2006). The meta-analysis of Blume et al. (2010) reaches the conclusion that the Big Five main dimensions have a small influence on the transfer of the learned material. Merely the dimension of conscientiousness can have moderate links with transfer of training ascribed to it (Blume et al., 2010). The meta-analysis of Colquitt et al. (2000) substantiates a moderate to strong influence of conscientiousness on transfer of training and work performance. Contrary to expectations, however, this meta-analysis also demonstrates significant negative effects of conscientiousness on the different forms of learning as well as participant reaction to training measures (Colquitt et al., 2000). Hinrichs (2014) and Herold, Davis, Fedor, and Parsons (2002) were unable to substantiate any significant impact of conscientiousness on transfer of training or learning. Further papers (Colquitt et al., 2000; Rowold, 2007) also show a negative, though not significant, impact of the dimension of conscientiousness on learning and transfer motivation. This result is contradicted by the study of Colquitt and Simmering (1998), which substantiates a significant positive impact of conscientiousness on learning motivation, before and after training. Altogether, the current body of evidence regarding the influence that the personality factor conscientiousness has on transfer of training is heterogeneous. The meta-analysis of Colquitt et al. (2000) does not, as expected, demonstrate a negative impact of the factor of anxiety on transfer of training and work performance. In regard to the dimension of neuroticism, the meta-analysis of Blume et al. (2010) also defies expectations by demonstrating a positive connection with transfer of training. The study 
of Machin and Fogarty (2004), on the other hand, contradicts these findings with its own, as it substantiates a significant negative influence of a persons negative affectivity on transfer intention. Herold et al. (2002) also determine that emotional stability has a significantly positive effect on learning. Negative relationships between the variables anxiety and emotional instability and learning and transfer motivation, on the other hand, are revealed by several studies (e.g., Colquitt et al., 2000; Rowold, 2007; Webster and Martocchio, 1993). The meta-analysis of Blume et al. (2010) substantiates a positive relationship between the dimension of extraversion and transfer. Naquin and Holton (2002) were unable to find any link between these personality traits and the transfer motivation of participants. The study conducted by Rowold (2007), however, confirms that introversion has a strong negative influence on learning and transfer motivation. Empirical findings are also inconsistent in regard to the factor of agreeableness. Whereas Blume et al. (2010) highlight a negative relationship between the factor of agreeableness and transfer of training, the study conducted by Rowold (2007) determines that the dimension of agreeableness has a positive influence on both learning and transfer motivation. However, Rowold (2007) questions any link between the personality trait openness to experiences and transfer in his study, Herold et al. (2002) confirm a positive impact of this variable on learning, and Blume et al. (2010) even a positive influence on transfer of training. On the whole, the studies regarding the influence of the five main dimensions of personality on learning and transfer processes indicate an inconsistent and partially diametrical body of evidence. Only few studies examine the influence of these determinants on the transfer of training level of evaluation. As a result, more research is necessary in order to obtain a sufficient and empirically validated understanding of the relationship between the distinct personality traits and transfer of training.

Expected utility. Different studies have determined a significant positive influence of the individually expected utility of participation in a training measure on transfer of training (Axtell et al., 1997; Bates et al., 2000; Lim and Morris, 2006; Renta-Davids et al., 2014; Velada and Caetano, 2007) and/or transfer motivation (Ruona et al., 2002; Van der Locht et al., 2013). The Renta-Davids et al. (2014) study has also demonstrated that the perceived relevance of training functions as a mediator between the complexity of the work task and transfer of training. In summary, both the determinants of the expected individual benefit as well as the determinant of the expected individual relevance are under-explored. Nevertheless, the few existing studies display corresponding results. However, future research should further examine the relationship between these determinants in order to validate findings. In addition, future studies should focus on more details, for example by incorporating mediating determinants like Renta-Davids et al. (2014), in order to reveal interdependencies and further specifics of the underlying process of transfer of training.

Individual goal intention. Smith, Jayasuriya, Caputi, and Hammer (2008) have developed and empirically tested a model based on the expected-value-theory of Vroom (1964) and the goal-theory (Gollwitzer, 1996). The results of this study show that goal 
intentions are a strong significant predictor for affective reaction, perceived utility and intention to transfer training. They show that these, in combination with the proximal determinants of self-efficacy, expectancy and valence positively influence the outcomes on the examined levels of affective reactions, utility reactions and transfer intentions. Goal intentions are also a significant mediator of the relationship between the variables valence and reactions (both affective and utility), but only a partial mediator between valence and intention to transfer. The authors (Smith et al., 2008) interpret these finding as a confirmation of goal intentions having the same significant mediatory role as the construct of training motivation in the model of Colquitt et al. (2000).

\subsection{Summary}

Our comprehensive analysis clarifies, that the current state of research regarding major determinants of the process of transfer of training indicates there are a lot of positive relationships at the three levels. We identify a lot of determinants related to organizational, learning field and individual level which have a positive consistent relationship with transfer of training, as depicted in figure 2. However, it has too often not yet been clarified in detail, what specific dimensions of these complex constructs cause this positive influence. Here, further studies are necessary, which focus on the partial dimensions in detail. In summary, Table 2 provides a comprehensive overview of the state of research on empirically confirmed statistically significant determinants and their dimensions on the respective characteristic levels. This table summarizes the identified significant results and makes clear what really matters in regard to the support of transfer of training. Overall, our analysis shows for the organizational level of the work environment, that transfer of training indicates positive relationships. The two most important determinants of the transfer within this level are social support and structural and organizational circumstances in the workplace. The focus of previous research was on the determinant of social support, however. Numerous studies confirm the positive influence of social support from colleagues and from supervisors, particularly in regard to the role played by feedback. Only a single study indicates an inconsistency in research findings regarding the determinant of support by supervisors. Further studies should investigate in detail which specific dimensions of support, beyond feedback, cause this positive influence. This also applies to the variables of structural and organizational circumstances in the workplace, identified in previous research. Only a handful of studies have investigated these, thus far. The dimensions of the determinant of organizational culture have already been partially incorporated in research.

A comprehensive understanding regarding the influence of this determinant on transfer of learning is still missing, however. For example, future studies should also examine in greater detail which specifics dimensions of organizational commitment cause the positive effect. Less well examined, is the influence of specific characteristics of training measurers on transfer of training. Some research has been done on the learning field level influence of transfer-boosting measures during a training measure. Several studies have concurrently shown that a high practical relevance of content, the biggest degree of similarity between the learning and application situations possible, and a learning 


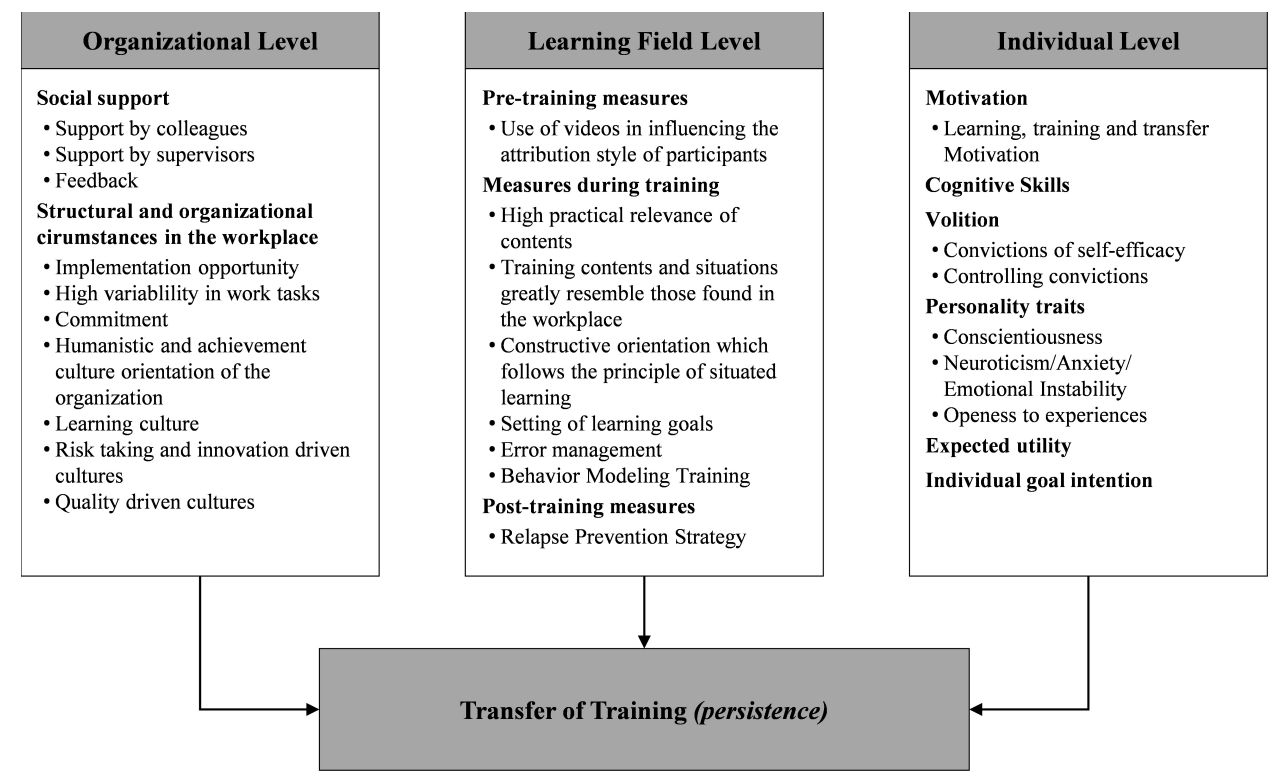

Figure 2: Empirically confirmed significant positive determinants on the transfer of training and their dimensions.

environment with features of situated learning, as well as the specification of learning targets, have a positive influence on transfer of training. Often it has not yet been clarified in detail, what specific dimensions of these complex constructs cause this positive influence, so further research is needed. In regard to the methodical-didactic design of training measures, for example, the influences of method variation, transfer tasks, content structuring and cognitive activation have not been examined. Little research has been done into the influence of specific transfer-boosting measures undertaken before or after a training measure. Again, further research to this end should bring greater clarity, for example regarding the influence of prior tasks, assignment clarification, critical incident surveys or follow-ups. What surprises about the presented analyses, is that, on the learning field level, there are currently no findings regarding the influence of personal characteristics and the expertise of the trainer. As table 1 shows, however, an influence of the didactic-methodological abilities is assumed by the central learning transfer models. A considerable deficit of research exists in this regard. Overall, it must be observed that further research should be more focused on a more detailed examination of training design as a determinant on transfer of training. 
Table 2: Determinants on the Transfer of Training, their Dimensions and Results of Meta-analysis.

\begin{tabular}{|c|c|c|c|}
\hline $\begin{array}{l}\text { Level of } \\
\text { characteristics }\end{array}$ & $\begin{array}{l}\text { Empirically } \\
\text { studied transfer } \\
\text { determinants }\end{array}$ & $\begin{array}{l}\text { Transfer of Training } \\
\text { positiv }\end{array}$ & negative \\
\hline \multirow[t]{11}{*}{$\begin{array}{l}\text { Organizational } \\
\text { level } \\
\text { (characteristics of } \\
\text { the work } \\
\text { environment) }\end{array}$} & \multirow[t]{3}{*}{ Social support } & $\begin{array}{l}\text { Support by colleagues: } \\
\text { Bates et al., 2000; Blume et al., } 2010 \text { (meta- } \\
\text { analysis); Cromwell \& Kolb, 2004; Facteau et } \\
\text { al., 1995; Festner, 2012; Homklin et al., 2014; } \\
\text { Martin, 2010; Ng, 2013; Ng \& Ahm, 2011 }\end{array}$ & \\
\hline & & $\begin{array}{l}\text { Support by supervisors: } \\
\text { Blume et al., } 2010 \text { (meta-analysis); Cromwell } \\
\text { \& Kolb, 2004; Festner, 2012; Lee et al., 2014; } \\
\text { Ng \& Ahm, 2011; Scaduto et al., 2008; } \\
\text { Hinrichs, } 2014 \text { (action-related support) }\end{array}$ & $\begin{array}{l}\text { Support by } \\
\text { supervisors: } \\
\text { Facteau et al., } 1995\end{array}$ \\
\hline & & $\begin{array}{l}\text { Feedback: } \\
\text { Goodman et al., 2011; Van den Bossche et al., } \\
\text { 2010; Velada et al., } 2007\end{array}$ & $\begin{array}{l}\text { Frequency of } \\
\text { feedback: } \\
\text { Van den Bossche et } \\
\text { al., } 2010\end{array}$ \\
\hline & \multirow{8}{*}{$\begin{array}{l}\text { Structural and } \\
\text { organizational } \\
\text { circumstances } \\
\text { in the workplace }\end{array}$} & $\begin{array}{l}\text { Implementation opportunity: } \\
\text { Cromwell \& Kolb, 2004; Ford et al., 1992; } \\
\text { Holton et al., 2000; Seidel, } 2012\end{array}$ & \\
\hline & & $\begin{array}{l}\text { Variability in work tasks: } \\
\text { Davids et al., } 2014\end{array}$ & \\
\hline & & $\begin{array}{l}\text { Commitment: } \\
\text { Facteau et al., 1995; Kontoghiorghes, } 2004\end{array}$ & \\
\hline & & $\begin{array}{l}\text { Organizational climate: } \\
\text { Lim \& Morris, } 2006\end{array}$ & \\
\hline & & $\begin{array}{l}\text { Performance and person-oriented } \\
\text { organizations: } \\
\text { Simosi, } 2012\end{array}$ & \\
\hline & & $\begin{array}{l}\text { Learning culture: } \\
\text { Egan et al., 2004; Martin, } 2010\end{array}$ & \\
\hline & & $\begin{array}{l}\text { Risk taking and innovation driven cultures: } \\
\text { Kontoghiorges, } 2004\end{array}$ & \\
\hline & & $\begin{array}{l}\text { Quality driven cultures: } \\
\text { Kontoghiorges, } 2004\end{array}$ & \\
\hline \multirow{5}{*}{$\begin{array}{l}\text { Learning field } \\
\text { level } \\
\text { (characteristics of } \\
\text { the training } \\
\text { measure) }\end{array}$} & $\begin{array}{l}\text { Pre-training } \\
\text { measures }\end{array}$ & $\begin{array}{l}\text { Use of videos in influencing the attribution- } \\
\text { style of participants: } \\
\text { Weissbein et al., } 2011\end{array}$ & \\
\hline & \multirow[t]{4}{*}{$\begin{array}{l}\text { Measures during } \\
\text { training }\end{array}$} & $\begin{array}{l}\text { High practical relevance of contents: } \\
\text { Seidel, 2012; Bates et al., } 2000\end{array}$ & \\
\hline & & $\begin{array}{l}\text { Training contents and situations greatly } \\
\text { resemble those found in the workplace: } \\
\text { Hinrichs, 2014; Van der Locht et al., } 2013\end{array}$ & \\
\hline & & $\begin{array}{l}\text { Constructivist orientation which follows the } \\
\text { principle of situated learning: } \\
\text { Weisweiler, } 2008\end{array}$ & \\
\hline & & $\begin{array}{l}\text { Setting of learning goals: } \\
\text { Blume et al., 2010; Brown, 2005; Johnson et } \\
\text { al., 2012; Lee \& Pucel, 1998; Richman- } \\
\text { Hirsch, 2001; Werner et al.,1994 }\end{array}$ & \\
\hline
\end{tabular}




\begin{tabular}{|c|c|c|c|}
\hline & \multirow[b]{3}{*}{$\begin{array}{l}\text { Post-training } \\
\text { measures }\end{array}$} & \multicolumn{2}{|l|}{$\begin{array}{l}\text { Error management: } \\
\text { Gully et al., 2002; Heimbeck et al., 2003; } \\
\text { Keith \& Frese, } 2008 \text { (meta-analysis) }\end{array}$} \\
\hline & & \multicolumn{2}{|l|}{$\begin{array}{l}\text { Behavior Modeling Training: } \\
\text { Taylor et al., } 2005 \text { (meta-analysis) }\end{array}$} \\
\hline & & \multicolumn{2}{|l|}{$\begin{array}{l}\text { Relapse prevention strategy: } \\
\text { Noe et al., 1990; Tziner et al., } 1991\end{array}$} \\
\hline \multirow[t]{9}{*}{$\begin{array}{l}\text { Individual level } \\
\text { (characteristics of } \\
\text { participants) }\end{array}$} & $\begin{array}{l}\text { Learning, } \\
\text { training and } \\
\text { transfer } \\
\text { motivation }\end{array}$ & $\begin{array}{l}\text { Axtell et al., 1997; Bhatti et al., 2013; } \\
\text { Chiaburu \& Lindsay, 2008; Chiaburu et al., } \\
\text { 2010; Facteau et al., 1995; Grohmann et al., } \\
\text { 2014; Hinrichs, 2014; Kontoghiorghes, 2004; } \\
\text { Lee et al., 2014; Liebermann \& Hoffmann, } \\
\text { 2008; Renta-Davids et al., 2014; Scaduto et } \\
\text { al., 2008; Tziner et al., 2007; Quiñones, 1995; } \\
\text { Van den Bossche et al., 2010; Van der Locht } \\
\text { et al., } 2013\end{array}$ & \\
\hline & Cognitive skills & $\begin{array}{l}\text { Blume et al. } 2010 \text { (meta-analysis); } \\
\text { Lee et al., } 2014\end{array}$ & \\
\hline & Volition & $\begin{array}{l}\text { Convictions of self-efficacy } \\
\text { Blume et al. } 2010 \text { (meta-analysis); Chiaburu, } \\
\text { et al., 2010; Colquitt et al., } 2000 \text { (meta- } \\
\text { analysis); Ford et al., 1998; Holladay \& } \\
\text { Quiñones, 2003; Mathieu et al., 1993; Simosi, } \\
\text { 2012; Tziner et al., 2007; Velada et al., } 2007\end{array}$ & \\
\hline & & $\begin{array}{l}\text { Controlling convictions } \\
\text { Tziner et al., 1991; } \\
\text { Colquitt et al., } 2000 \text { (meta-analysis) }\end{array}$ & $\begin{array}{l}\text { Blume et al., } 2010 \\
\text { (meta-analysis) }\end{array}$ \\
\hline & $\begin{array}{l}\text { Personalitiy } \\
\text { traits }\end{array}$ & $\begin{array}{l}\text { Conscientiousness: } \\
\text { Blume et al., } 2010 \text { (meta-analysis); Colquitt et } \\
\text { al., } 2010 \text { (meta-analysis) }\end{array}$ & $\begin{array}{l}\text { Agreeableness: } \\
\text { Blume et al. } 2010 \\
\text { (meta-analysis) }\end{array}$ \\
\hline & & $\begin{array}{l}\text { Neuroticism/Anxiety/Emotional Instability: } \\
\text { Blume et al., } 2010 \text { (meta-analysis); Colquitt et } \\
\text { al., } 2010 \text { (meta-analysis); Herold et al., } 2002\end{array}$ & $\begin{array}{l}\text { Negative } \\
\text { Affectivity: } \\
\text { Machin \& Fogarty, }\end{array}$ \\
\hline & & $\begin{array}{l}\text { Openness to experiences: } \\
\text { Blume et al., } 2010 \text { (meta-analysis) }\end{array}$ & 2004 \\
\hline & Expected utility & $\begin{array}{l}\text { Axtell et al., 1997; Bates et al., 2000; Lim \& } \\
\text { Morris, 2006; Renta-Davids et al., 2014; } \\
\text { Velada \& Caetano, } 2007\end{array}$ & \\
\hline & $\begin{array}{l}\text { Individual goal } \\
\text { intention }\end{array}$ & Smith et al., 2008 & \\
\hline
\end{tabular}

The analysis makes clear, that characteristics of participants play a central role in the process of transfer of training. At the individual level a lot of studies indicate a positive relationship between learning, training and transfer motivation, cognitive skills, and volitional determinants and transfer of training. However, it has too often not yet been clarified in detail, what specific dimensions of these complex constructs cause this positive influence. Less clear, however, are the results of the studies regarding the influence of controlling convictions and personality traits. Here, the findings are not consistent. Also the impact of individual goal intention of the participants on the transfer of training is under-explored. In particular, future research should examine the determinants of controlling convictions, personality traits and individual goal intention, to bring more clarity about their influence on transfer of training. 


\section{Discussion and Implications for Further Research}

On the whole, analysis of the existing research literature concerning the determinants of transfer of training presented herein shows that there are, by now, numerous empirical studies concerned with specific partial aspects of transfer of training. Still, the analysis makes clear that the current state of research regarding determinants of the process of transfer of training shows a lot of positive and consistent relationships between different determinants at the three levels and the transfer of training. Particularly the individual level has been examined comparatively frequently and well, with the research show the learning, training and transfer motivation in particular to be a key concept of transfer of training. In regard to the institutional and learning field levels, numerous determinants have been the subject of little or no research, making this another area in considerable need of investigation. Many questions, particularly in regard to the dimensions of the determinants remain unanswered. Here, further research is necessary, which investigates partial dimensions in detail. Finally, in the context of the limitations of the review, perspectives for further research projects are highlighted. (1) Although this literature review was able to identify numerous studies examining determinants which boost transfer of training, the structural relationships of and between the latent and manifest variables and interdependencies remain largely ignored. Despite comprehensive studies within the framework of transfer research, the emerging picture is that even though the process of transfer of training is influenced by input, process and output determinants on the organizational, learning field and individual level, past studies have focused only on a very specific partial aspect of transfer of training. There is, right now, no comprehensive, integrative examination of transfer of training under consideration of training offers (input), the transfer process (process) and the results (output) as well as a systematic analysis of which important determinants boost or hinder transfer. In order to do the actual complexity of the transfer process justice, there should be a greater understanding of it as a multidimensional process (Burke and Hutchins, 2007; Gessler, 2012). The predictors, mediators, moderators and their relationships amongst each other, as well as underlying processes are yet to be worked out (Weisweiler et al., 2013). Future examinations should therefore attempt to assume a more comprehensive and integrative perspective when determining transfer of training effects and determinants thereof. This can be done by examining not just results but also process determinants in order to give ample consideration to the interaction between the fields of learning and function (Gessler, 2012). Only by adopting such an integrated research approach can both the aspects of efficacy control and development of training measures under consideration of aspects of transfer of training be done justice. This, in turn, would lead to a qualitative improvement of transfer research. In order to so, theory-driven, interdisciplinary research is required (Blume et al., 2010; Gruber, 2013; Weisweiler et al., 2013). The theoretical foundation of the studies is based mostly on those models of transfer, which are based on the three levels. In regard to the influence of the individual level, various psychological theories are consulted. The competence debate highly relevant to this context has, however, also been neglected by training research thus far. Only Seidel (2012) has defined the construct of transfer competence as an individual-specific disposition. In this context, this 
review was based on an expanded understanding of transfer (see p. 7). For the further substantiation of the organizational level, greater use of organizational research theories could be made. In regard to the learning field level, the findings of pedagogical and psychological teaching and learning research have thus far been mostly neglected. Hence, future studies should refer more strongly to the theories of related disciplines. This would contribute to the development of a holistic model for the explanation of learning transfer. An interdisciplinary approach to theory and research would therefore be fruitful. (2) The comparability of studies in regard to methodological aspects is limited. The studies included are not distinguished by a consistent application of terminology. Hence, the review assigned different constructs to transfer of training. Typical examples for this are the constructs perceived transfer of training versus transfer of training versus learning transfer. The difficulties in the creation of a literature review arose mainly from constructs which are imprecisely explicated, or overlap semantically. Typical examples for this are the constructs learning motivation versus training motivation and intention to transfer versus transfer motivation. The authors constructed their own questionnaires, employing different scales. The psychometric quality of the employed instruments is therefore to be viewed critically (Egan et al., 2004; Holton et al., 2000; Pham et al., 2013). Until now, the only existing valid instrument containing transfer-relevant scales is the LTSI (Holton et al., 2000). This intends to permit a multi-dimensional analysis of the transfer process and the establishment of comparability between studies. (3) Only quantitative research results were considered in the literature review. Weisweiler et al. (2013) stated that the currently existing quantitative measuring instruments are in no way sufficient to cope with the complexity of the transfer process. In the context of the scope and limitations of the currently available statistical processes, the question is raised in how far such complex relationships as the transfer process and its determinants can be sufficiently measured at all. Hence, it can be assumed that quantitative research designs reach their limitations, particularly in regard to the dimensions of determinants. Qualitative research may reach differentiated conclusions, in this regard. In future, it should thus be examined what conclusions qualitative research designs reach regarding determinants and their dimensions of transfer of training. (4) The focus of the literature review is entirely on formalized training measures. Baldwin et al. (2009), in the context of the increasing importance and diversity of vocational training, point out the need to include, for example, e-learning in future studies. In order to make a contribution to answering the extremely important question of which differences exist between different forms and types of training measure due to their respective setting of targets and with regard to their short-, mid-, and long-term transfer of training efficacy, and which field-of-learning-specific determinants influence them significantly, future studies should examine the efficacy, as represented by the measured transfer of training, of typical types of training measure (such as specialized versus interdisciplinary training measures, or formalized versus workplace-related and job-related training measures). Further empirically confirmed knowledge concerning transfer of training efficacy and its determinants and their dimensions are, however, urgently required in order to improve the effectiveness of formalized training in practice (see p. 4). This permits the immediate comparison of different organizational forms of training in regard to their transfer 
efficacy and persistence. This, in turn, permits us to differentiate between more and less effective training measures, determine causes and determinants for transfer success (or failure) and deduce recommendations for the systematic promotion of transfer of training, on a solid empirical foundation. 


\section{References}

Alliger, G. M., Tannenbaum, S. I., Bennett, W., Traver, H., \& Shotland, A. (1997). A meta-analysis of the relations among training criteria. Personnel Psychology, 50, 341-358. doi:10.1111/j.1744-6570.1997.tb00911.x

Arthur, W., Bennett, W., Edens, P. S., \& Bell, S. T. (2003). Effectiveness of training in organizations: A meta-analysis of design and evaluation features. Journal of Applied Psychology, 88, 234-245. doi:10.1037/0021-9010.88.2.234

Axtell, C. M., Maitlis, S., \& Yearta, S. K. (1997). Predicting immediate and longerterm transfer of training. Personnel Review, 26, 201-213. doi:10.1108/00483489710161413

Baldwin, T. T., \& Ford, J. K. (1988). Transfer of training: A review and directions for future research. Personnel Psychology, 41, 63-105. doi:10.1111/j.17446570.1988.tb00632.x

Baldwin, T. T., Ford, J. K., \& Blume, B. D. (2009). Transfer of training 1988-2008: An updated review and agenda for future research. International Review of Industrial and Organizational Psychology, 24, 41-70. doi:10.1002/9780470745267.ch2

Bandura, A. (1982). Self-efficacy mechanism in human agency. American Psychologist, 37, 122-147. doi:10.1037/0003-066X.37.2.122

Barba Aragon, I., \& Sanz Valle, R. (2012). Does training managers pay off? The International Journal of Human Resource Management, 24, 1-14. doi:10.1080/09585192.2012.725064

Bates, R. A., \& Holton, E. F. (2004). Linking workplace literacy skills and transfer system perceptions. Human Resource Development Quarterly, 15, 153-170. doi:10.1002/hrdq.1096

Bates, R. A., Holton, E. F., Seyler, D. L., \& Carvalho, M. A. (2000). The role of interpersonal factors in the application of computer-based training in an industrial setting. Human Resource Development International, 3, 19-42. doi: $10.1080 / 136788600361920$

Bhatti, M. A., Battour, M. M., Sundram, V. P. K., \& Othman, A. A. (2013). Transfer of training: does it truly happen?: An examination of support, instrumentality, retention and learner readiness on the transfer motivation and transfer of training. European Journal of Training and Development, 37, 273-297. doi:10.1108/03090591311312741

Blume, B. D., Ford, J. K., Baldwin, T. T., \& Huang, J. L. (2010). Transfer of training: A meta-analytic review. Journal of Management, 36, 1065-1105. doi: $10.1177 / 0149206309352880$

Brown, T. C. (2005). Effectiveness of distal and proximal goals as transfer-of-training interventions: A field experiment. Human Resource Development Quarterly, 16, 369-387. doi:10.1002/hrdq.1144

Burke, L. A. (1997). Improving positive transfer: A test of relapse prevention training on transfer outcomes. Human Resource Development Quarterly, 8, 115-128. doi: $10.1002 /$ hrdq. 3920080204 
Burke, L. A., \& Baldwin, T. T. (1999). Workforce training transfer: A study of the effect of relapse prevention training and transfer climate. Human Resource Management, 38, 227-242.

Burke, L. A., \& Hutchins, H. M. (2007). Training transfer: An integrative literature review. Human Resource Development Review, 6, 263-296. doi:10.1177/1534484307303035

Cannon-Bowers, J. A., Tannenbaum, S. I., \& Mathieu, J. E. (1995). Toward theoretically based principles of training effectiveness: A model and initial empirical investigation. Military Psychology, 7, 141-164. doi:10.1207/s15327876mp0703_1

Carter, S. D. (2002). Matching training methods and factors of cognitive ability: A means to improve training outcomes. Human Resource Development Quarterly, 13, 71-87. doi:10.1002/hrdq.1014

Cheng, E. W. L. (2000). Test of the MBA knowledge and skills transfer. The International Journal of Human Resource Management, 1, 837-852. doi:10.1080/09585190050075150

Cheng, E. W. L., \& Hampson, I. (2008). Transfer of training: A review and new insights. International Journal of Management Reviews, 10, 327-341. doi: 10.1111/j.1468-2370.2007.00230.x

Cheng, E. W. L., \& Ho, D. C. K. (2001). A review of transfer of training studies in the past decade. Personnel Review, 30, 102-118. doi:10.1108/00483480110380163

Chiaburu, D. S., \& Lindsay, D. R. (2008). Can do or will do? The importance of selfefficacy and instrumentality for training transfer. Human Resource Development International, 11, 199-206. doi:10.1080/13678860801933004

Chiaburu, D. S., \& Marinova, S. V. (2005). What predicts skill transfer? An exploratory study of goal orientation, training self-efficacy and organizational supports. International Journal of Training and Development, 9, 110-123. doi:10.1111/j.1468-2419.2005.00225.x

Chiaburu, D. S., Van Dam, K., \& Hutchins, H. M. (2010). Social support in the workplace and training transfer: a longitudinal analysis. International Journal of Selection and Assessment, 18, 187-200. doi:10.1111/j.146-2389.2010.00500.x

Clarke, N. (2002). Jobwork environment factors influencing training transfer within a human service agency: Some indicative support for Baldwin and Fords' transfer climate construct. International Journal of Training and Development, 6 , 146-162. doi:10.1111/1468-2419.00156

Colquitt, J. A., LePine, J. A., \& Noe, R. A. (2000). Toward an integrative theory of training motivation: A meta-analytic path analysis of 20 years of research. Journal of Applied Psychology, 85, 678-707. doi:10.1037//0021-9010.85.5.678

Colquitt, J. A., \& Simmering, M. J. (1998). Conscientiousness, goal orientation, and motivation to learn during the learning process: A longitudinal study. Journal of Applied Psychology, 83, 654-665. doi: 10.1037//0021-9010.83.4.654

Costa, P. T., \& McCrae, R. R. (1995). Domains and facets: Hierarchical personality assessment using the revised NEO personality inventory. Journal of Person- 
ality Assessment, 64, 21-50. doi:10.1207/s15327752jpa6401_2

Cromwell, S. E., \& Kolb, J. A. (2004). An examination of work-environment support factors affecting transfer of supervisory skills training to the workplace. Human Resource Development Quarterly, 15, 449-471. doi:10.1002/hrdq.1115

Diesner, I., \& Seufert, S. (2010). Trendstudie 2010. Herausforderungen für das Bildungmanagement in Unternehmen [Trend study 2010. Challenges for the educational management in companies]. St. Gallen, Switzerland: Swiss Centre for Innovations in Learning.

Diesner, I., \& Seufert, S. (2013). Trendstudie 2012. Herausforderungen für das Bildungmanagement in Unternehmen [Trend study 2012. Challenges for the educational management in companies]. St. Gallen, Switzerland: Swiss Centre for Innovations in Learning.

Diesner, I., Seufert, S., \& Euler, D. (2008). Trendstudie 2008. Herausforderungen für das Bildungsmanagement in Unternehmen [Trend study 2008. Challenges for the educational management in companies]. St. Gallen, Switzerland: Swiss Centre for Innovations in Learning.

Dubs, R. (1994). Management-Ausbildung: ein altes Thema erneut betrachtet [Management training: an old topic new considered]. In R. Hasenböhler, R. Kiechel, \& J.-P. Thommen (Eds.), Zukunftsorientierte Management-Ausbildung [Future-oriented management training ](pp.16-40). Zürich, Switzerland: Versus-Verlag.

Egan, T. M., Yang, B., \& Bartlett, K. R. (2004). The effects of organizational learning culture and job satisfaction on motivation to transfer learning and turnover intention. Human Resource Development Quarterly, 15, 279-301. doi: $10.1002 /$ hrdq. 1104

Ellström, E., \& Ellström, P.-E. (2014). Learning outcomes of a work-based training programme: The significance of managerial support. European Journal of Training and Development, 38, 180-197. doi:10.1108/EJTD-09-2013-0103

Facteau, J. D., Dobbins, G. H., Russell, J. E. A., Ladd, R. T., \& Kudisch, J. D. (1995). The influence of general perceptions of the training environment on pretraining motivation and perceived training transfer. Journal of Management, 21, 1-25. doi:10.1177/014920639502100101

Festner, D. (2012). Veränderbarkeit betrieblichen Handelns. Transfer unter Einfluss von Merkmalen der Lernperson, der Lern- und Arbeitsumgebung [Changeability of operative actions. The influence of learners characteristics, learning, and working environment on transfer of training]. Frankfurt am Main, Germany: Peter Lang.

Ford, J. K., Quiñones, M. A., Sego, D. J., \& Sorra, J. S. (1992). Factors affecting the opportunity to perform trained tasks on the job. Personnel Psychology, 45, 511-527. doi:10.1111/j.1744-6570.1992.tb00858.x

Ford, J. K., Smith, E. M., Weissbein, D. A., Gully, S. M., \& Salas, E. (1998). Relationships of goal orientation, metacognitive activity, and practice strategies with learning outcomes and transfer. Journal of Applied Psychology, 83, 218-233. doi:10.1037//0021-9010.83.2.218 
Gaudine, A. P., \& Saks, A. M. (2004). A longitudinal quasi-experiment on the effects of posttraining transfer interventions. Human Resource Development Quarterly, 15, 57-76. doi:10.1002/hrdq.1087

Gegenfurtner, A., Festner, D., Gallenberger, W., Lehtinen, E., \& Gruber, H. (2009). Predicting autonomous and controlled motivation to transfer training. International Journal of Training and Development, 13, 124-138. doi:10.1111/j.1468-2419.2009.00322.x

Gegenfurtner, A., Veermans, K., \& Vauras, M. (2013). Effects of computer support, collaboration, and time lag on performance selfefficacy and transfer of training: A longitudinal meta-analysis. Educational Research Review, 8, 75-89. doi:10.1016/j.edurev.2012.04.001

Georgenson, D. L. (1982). The problem of transfer calls for partnership. Training \& Development Journal. Retrieved from http://psycnet.apa.org/psycinfo/198304546-001

Gessler, M. (2012). Lerntransfer in der beruflichen Weiterbildung - empirische Prüfung eines integrierten Rahmenmodells mittels Strukturgleichungsmodellierung (Transfer of training of vocational training - empirical validation of an integrated framework with structual equation modelling). Zeitschrift für Berufsund Wirtschaftspädagogik, 108, 362-393.

Gollwitzer, P. M. (1996). The volitional benefits of planning. In P. M. Gollwitzer \& J. A. Bargh (Eds.), The Psychology of action. Linking cognition and motivation to behavior (pp. 287-312). New York, NY: Guilford Press.

Goodman, J. S., Wood, R. E., \& Chen, Z. (2011). Feedback specificity, information processing, and transfer of training. Organizational Behavior and Human Decision Processes, 115, 253-267. doi:10.1016/j.obhdp.2011.01.001

Grohmann, A., Beller, J., \& Kauffeld, S. (2014). Exploring the critical role of motivation to transfer in the training transfer process. International Journal of Training and Development, 18, 84-103. doi:10.1111/ijtd.12030

Grossman, R., \& Salas, E. (2011). The transfer of training: What really matters. International Journal of Training and Development, 15, 103-120. doi:10.1111/j.1468-2419.2011.00373.x

Gruber, H. (2013). Marathon running, accreditation of study programmes and professional development in consultancies: Are they all about the same? A cognitive perspective on transfer of training. Educational Research Review, 8, 96-101. doi:10.1016/j.edurev.2012.11.006

Gully, S. M., Payne, S. C., Koles, K. L. K., \& Whiteman, J.-A. K. (2002). The impact of error training and individual differences on training outcomes: An attribute-treatment interaction perspective. Journal of Applied Psychology, 87, 143-155. doi:10.1037//0021-9010.87.1.143 
Hasselhorn, M., \& Mähler, C. (2000). Transfer: Theorien, Technologien und empirische Erfassung [Transfer: Theories, technologies, and empirical analysis]. In W. Hager, J.-L. Patry, \& H. Brezing (Eds.), Evaluation psychologischer Interventionsmanahmen. Standards und Kriterien: Ein Handbuch [Evaluation of psychological intervention measures. Standards and criteria: A manual] (pp. 86-101). Bern, Switzerland: Huber.

Heimbeck, D., Frese, M., Sonnentag, S., \& Keith, N. (2003). Integrating errors into the training process: the function of error management instructions and the role of goal orientation. Personnel Psychology, 56, 333-361. doi:10.1111/j.17446570.2003.tb00153.x

Herold, D. M., Davis, W., Fedor, D. B., \& Parsons, C. K. (2002). Dispositional influences on transfer of learning in multistage training programs. Personnel Psychology, 55, 851-869. doi:10.1111/j.1744-6570.2002.tb00132.x

Hinrichs, A.-C. (2014). Predictors of collateral learning transfer in continuing vocational training. International Journal for Research in Vocational Education and Training, 1 (1), 35-56. doi:10.13152/IJRVET.1.1.3

Holladay, C. L., \& Quiñones, M. A. (2003). Practice variability and transfer of training: The role of self-efficacy generality. Journal of Applied Psychology, 88, 1094-1103. doi:10.1037/0021-9010.88.6.1094

Holton, F. E., Bates, R. A., \& Ruona, W. E. A. (2000). Development of a generalized learning transfer system inventory. Human Resource Development Quarterly, 11, 333-360.

Homklin, T., Takahashi, Y., \& Techakanont, K. (2014). The influence of social and organizational support on transfer of training: evidence from Thailand. International Journal of Training and Development, 18, 116-131. doi:10.1111/ijtd.12031

Hutchins, H. M., \& Burke, L. A. (2007). Identifying trainers' knowledge of training transfer research findings - closing the gap between research and practice. International Journal of Training and Development, 11, 236-264. doi:10.1111/j.1468-2419.2007.00288.x

Hutchins, H. M., Burke, L. A., \& Berthelsen, A. M. (2010). A Missing Link In The Transfer Problem? Examining How Trainers Learn About Training Transfer. Human Resource Management, 49, 599-618. doi:10.1002/hrm

Johnson, S. K., Garrison, L. L., Hernez-Broome, G., Fleenor, J. W., \& Steed, J. L. (2012). Go for the goal(s): Relationship between goal setting and transfer of training following leadership development. Academy of Management Learning and Education, 11, 555-569. doi:10.5465/amle.2010.0149

Kabst, R., Giardini, A., \& Wehner, M. C. (2009). International komparatives Personalmanagement. Evidenz, Methodik \& Klassiker des "Cranfield Projects on International Human Resource Management" [International comparative human resource management: Evidence, methodology \& classics of the 'Cranfield Projects on International Human Resource Management']. München, Mering, Germany: Rainer Hampp. 
Kauffeld, S., Bates, R., Holton III, E. F., \& Müller, A. C. (2008). Das deutsche Lerntransfer-System-Inventar (GLTSI): psychometrische Überprüfung der deutschsprachigen Version [The German version of the Learning Transfer Systems Inventory (GLTSI): Psychometric validation]. Zeitschrift für Personalpsychologie, 7, 50-69. doi:10.1026/1617-6391.7.2.50

Kauffeld, S., \& Grote. S. (2000). Weiterbildung - ein zerbrechender Mythos? [Further education - a breaking myth?]. In E. Frieling, S. Kauffeld, S. Grote, \& H. Bernard (Eds.), Flexibilität und Kompetenz. Schaffen flexible Unternehmen flexible und kompetente Mitarbeiter? [Flexibility and competence. Do flexible companies create flexible and competent employees?] (pp. 163-186). Münster, Germany: Waxmann.

Kauffeld, S., Lorenzo, G., \& Weisweiler, S. (2012).Wann wird Weiterbildung nachhaltig? Erfolg und Erfolgsfaktoren bei Lerntransfer [When do further trainings become sustainable? Success and factors of success in transfer of training]. Personal Quarterly, 64(2),10-15.

Keith, N., \& Frese, M. (2008). Effectiveness of error management training: A metaanalysis. Journal of Applied Psychology, 93, 59-69.

doi: $10.1037 / 0021-9010.93 .1 .59$

Kirkpatrick, D. L., \& Kirkpatrick, J. D. (2006). Evaluating training programs. The four levels (3rd ed.). San Francisco, CA: Berrett-Koehler.

Kontoghiorghes, C. (2001). Factors affecting training effectiveness in the context of the introduction of new technology - A US case study. International Journal of Training and Development, 5, 248-260. doi:10.1111/1468-2419.00137

Kontoghiorghes, C. (2002). Predicting motivation to learn and motivation to transfer learning back to the job in a service organization: A new systemic model for training effectiveness. Performance Improvement Quarterly, 15(3), 114-129. doi:10.1111/j.1937-8327.2002.tb00259.x

Kontoghiorghes, C. (2004). Reconceptualizing the learning transfer conceptual framework: empirical validation of a new systemic model. International Journal of Training and Development, 8, 210-221.

doi:10.1111/j.1360-3736.2004.00209.x

Laker, D. R., \& Powell, J. L. (2011). The differences between hard and soft skills and their relative impact on training transfer. Journal of the American Geriatrics Society, 22, 111-122. doi:10.1002/hrdq.20063

Lau, P. Y. Y., \& McLean, G. N. (2013). Factors influencing perceived learning transfer of an outdoor management development programme in Malaysia. Human Resource Development International, 16, 186-204. doi:10.1080/13678868.2012.756157

Lee, C., Lee, H., Lee, J., \& Park, J. (2014). A multiple group analysis of the training transfer model: Exploring the differences between high and low performers in a Korean insurance company. The International Journal of Human Resource Management, 25, 2837-2857. doi:10.1080/09585192.2014.934887

Lee, K., \& Pucel, D. J. (1998). The perceived impacts of supervisor reinforcement and learning objective importance on transfer of training. Performance Im- 
provement Quarterly, 11(4), 51-61. doi: 10.1111/j.1937-8327.1998.tb00106.x Lemke, S. (1995). Transfermanagement [Transfer management]. Göttingen, Germany: Verlag für Angewandte Psychologie.

Liebermann, S., \& Hoffmann, S. (2008). The impact of practical relevance on training transfer: Evidence from a service quality training program for German bank clerks. International Journal of Training and Development, 12, 74-86. doi:10.1111/j.1468-2419.2008.00296.x

Lim, D. H., \& Johnson, S. D. (2002). Trainee perceptions of factors that influence learning transfer. International Journal of Training and Development, 6, 3648. doi:10.1111/1468-2419.00148

Lim, D. H., \& Morris, M. L. (2006). Influence of trainee characteristics, instructional satisfaction, and organizational climate on perceived learning and training transfer. Human Resource Development Quarterly, 17, 85-115. doi:10.1002/hrdq.1162

Machin, M. A., \& Fogarty, G. J. (2004). Assessing the antecedents of transfer intentions in a training context. International Journal of Training and Development, 8, 222-236. doi:10.1111/j.1360-3736.2004.00210.x

Mandl, H., Prenzel, M., \& Gräsel, C. (1992). Das Problem des Lerntransfers in der betrieblichen Weiterbildung [The issue of transfer of training in further education]. Unterrichtswissenschaft, 20(2), 126-143.

Marsick, V. J., \& Watkins, K. E. (2003). Demonstrating the value of an organization's learning culture: The dimensions of the Learning Organization Questionnaire. Advances in Developing Human Resources, 5, 132-151. doi: $10.1177 / 1523422303005002002$

Martin, H. J. (2010). Workplace climate and peer support as determinants of training transfer. Human Resource Development Quarterly, 21, 87-104. doi:10.1002/hrdq.20038

Marx, R. D. (1982). Relapse prevention for managerial training: a model for maintenance of behavior change. The Academy of Management Review, 7, 433-441. doi:10.5465/amr.1982.4285359

Mathieu, J. E., Martineau, J. W., \& Tannenbaum, S. I. (1993). Individual and situational influences on the development of self-efficacy: Implications for training effectiveness. Personnel Psychology, 46, 125-147. doi:10.1111/j.1744-6570.1993.tb00870.x

Naquin, S. S., \& Holton, E. F. (2002). The effects of personality, affectivity, and work commitment on motivation to improve work through learning. Human Resource Development Quarterly, 13, 357-376. doi:10.1002/hrdq.1038

$\mathrm{Ng}, \mathrm{K} . \mathrm{H}$. (2013). The influence of supervisory and peer support on the transfer of training. Studies in Business and Economics, 8, 82-98.

Ng, K. H., \& Ahm, R. (2011). The impact of the supervisor's role in training programmes on the transfer of training: A case study in four east Malaysian local governments. Research and Practice in Human Resource Management, 19, $24-42$. 
Noe, R. A. (1986). Trainees attributes and attitudes: Neglected influences on training effectiveness. Academy of Management Review, 11, 736-749. doi:10.5465/amr.1986.4283922

Noe, R. A., \& Schmitt, N. (1986). The influence of trainee attitudes on training effectiveness: Test of a model. Personnel Psychology, 39, 497-523. doi:10.1111/j.1744-6570.1986.tb00950.x

Noe, R. A., Sears, J., \& Fullenkamp, A. M. (1990). Relapse training: Does it influence trainees' post training behavior and cognitive strategies? Journal of Business and Psychology, 4, 317-328. doi:10.1007/bf01125242

Pham, N. T. P., Segers, M. S. R., \& Gijselaers, W. H. (2013). Effects of work environment on transfer of training: Empirical evidence from Master of Business Administration programs in Vietnam. International Journal of Training and Development, 17, 1-19. doi:10.1111/j.1468-2419.2012.00417.x

Phillips, J.J. (1991). Measuring the return on HRD. Employment Relations Today, 18, 329-342.

Phillips, J. J., \& Phillips, P. P. (2001). The return on investment (ROI) process. In L. L. Ukens (Ed.) What smart trainers know: The secrets of success from the world foremost experts (pp. 133-159). San Francisco, CA: JosseyBass/Pfeiffer.

Phillips, J. J., Stone, R. D., \& Phillips, P. P. (2001). The human resources scorecard: Measuring the return on investment. Bosten, MASS.: ButterworthHeinemann.

Pidd, K. (2004). The impact of workplace support and identity on training transfer: A case study of drug and alcohol safety training in Australia. International Journal of Training and Development, 8, 274-288. doi:10.1111/j.13603736.2004.00214.x

Piezzi, D. (2002). Transferförderung in der betrieblichen Weiterbildung. Die Bedeutung der Arbeitsumgebung und der Integration der Weiterbildung in die Unternehmensführung [Supporting the transfer in further education. The influence of work environments and of the integration of further training into the management]. Paderborn, Germany: Eusl-Verlag.

Quiñones, M. A. (1995). Pretraining context effects: Training assignment as feedback. Journal of Applied Psychology, 80, 226-238. doi:10.1037//0021-9010.80.2.226

Rank, B., \& Wakenhut, R. (1998). Ein Bedingungsmodell des Praxistransfers [A model of practice transfer]. In B. Rank \& O. Wakenhut (Eds.), Sicherung des Praxistransfers im Führungskräftetraining [Ensuring practice transfer in leadership training] (pp. 11-30). München, Mering, Germany: Rainer Hampp.

Ree, M. J., \& Earles, J. A. (1991). Predicting training success: Not much more than g. Personnel Psychology, 44, 321-332. doi:10.1111/j.1744-6570.1991.tb00961.x

Renta-Davids, A.-I., Jiménez-González, J.-M., Fandos-Garrido, M., \& González-Soto, Á.-P. (2014). Transfer of learning. Motivation, training design and learning conducive work effects. European Journal of Training and Development, 38, 728-744. doi:10.1108/EJTD-03-2014-0026 
Richman-Hirsch, W. L. (2001). Posttraining interventions to enhance transfer: The moderating effects of work environments. Human Resource Development Quarterly, 12, 105-120. doi:10.1002/hrdq.2.abs

Rouiller, J. Z., \& Goldstein, I. L. (1993). The relationship between organizational transfer climate and positive transfer of training. Human Resource Development Quarterly, 4, 377-390. doi:10.1002/hrdq.3920040408

Rowold, J. (2007). The impact of personality on training-related aspects of motivation: Test of a longitudinal model. Human Resource Development Quarterly, 18, 9-31. doi:10.1002/hrdq.1190

Ruona, W. E., Leimbach, M., Holton III, E. F., \& Bates, R. A. (2002). The relationship between learner utility reactions and predicted learning transfer among trainees. International Journal of Training and Development, 6, 218-228. doi:10.1111/1468-2419.00160

Saks, A. M., \& Belcourt, M. (2006). An investigation of training activities and transfer of training in organizations. Human Resource Management, 45, 629-648. doi: $10.1002 / \mathrm{hrm} .20135$

Saks, A. M., \& Burke, L. A. (2012). An investigation into the relationship between training evaluation and the transfer of training. International Journal of Training and Development, 16, 118-127. doi:10.1111/j.1468-2419.2011.00397.x

Saks, A. M., \& Burke-Smalley, L. A. (2014). Is transfer of training related to firm performance? International Journal of Training and Development, 18, 104115. doi:10.1111/ijtd.12029

Scaduto, A., Lindsay, D., \& Chiaburu, D. S. (2008). Leader influences on training effectiveness: Motivation and outcome expectation processes. International Journal of Training and Development, 12, 158-170. doi:10.1111/j.14682419.2008.00303.x

Schuchmann, D., \& Seufert, S. (2013). Kompetenzentwicklung in Unternehmen. Neuorientierung betrieblicher Weiterbildung - Wege aus der "Kürsli-Denke"? [Developing competences in companies. Reorientation of further education Ways out of the "Kürsli-mentality"?]. In S. Seufert, \& C. Metzger (Eds.), Kompetenzentwicklung in unterschiedlichen Lernkulturen [Developing competences in different learning cultures] (pp. 421-442). Paderborn, Germany: Eusl.

Seidel, J. (2012). Transferkompetenz und Transfer. Theoretische und empirische Untersuchung zu den Wirksamkeitsbedingungen betrieblicher Weiterbildung [Transfer competence and transfer. A theoretical and empirical analysis of the conditions affecting effectiveness in further education]. Landau, Germany: Verlag Empirische Pädagogik.

Seyler, D. L., Holton, E. F., Bates, R. A., Burnett, M. F., \& Carvalho, M. A. (1998). Factors affecting motivation to transfer training. International Journal of Training and Development, 2, 2-16. doi:10.1111/1468-2419.00031

Simosi, M. (2012). The moderating role of self-efficacy in the organizational culturetraining transfer relationship. International Journal of Training and Develop- 
ment, 16, 92-106. doi:10.1111/j.1468-2419.2011.00396.x

Smith, R., Jayasuriya, R., Caputi, P., \& Hammer, D. (2008). Exploring the role of goal theory in understanding training motivation. International Journal of Training and Development, 12, 54-72. doi:10.1111/j.1468-2419.2007.00295.x

Solga, M. (2005). Management des Lerntransfers [Managing transfer of training]. In J. Ryschka, M. Solga, \& A. Mattenklott (Eds.), Praxishandbuch Personalentwicklung. Instrumente, Konzepte, Beispiele [Manual of human resource development: Instruments, concepts, examples] (pp. 269-291). Wiesbaden, Germany: Gabler.

Tannenbaum, S. I., Mathieu, J. E., Salas, E., \& Cannon-Bowers, J. A. (1991). Meeting trainees' expectations: The influence of training fulfillment on the development of commitment, self-efficacy, and motivation. Journal of Applied Psychology, 76, 759-769. doi:10.1037/0021-9010.76.6.759

Tannenbaum, S. I., \& Yukl, G. (1992). Training and development in work organizations. Annual Review of Psychology, 43, 399-441. doi:10.1146/annurev.ps.43.020192.002151

Taylor, P. J., Russ-Eft, D. F., \& Chan, D. W. L. (2005). A meta-analytic review of behavior modeling training. Journal of Applied Psychology, 90, 692-709. doi:10.1037/0021-9010.90.4.692

Thorndike, E. L., \& Woodworth, R. S. (1901). The influence of improvement in one mental function upon the efficiency of other functions. Psychological Review, 8(3), 247-261. doi:10.1037/h0074898

Tracey, J. B., Hinkin, T. R., Tannenbaum, S. I., \& Mathieu, J. E. (2001). The influence of individual characteristics and the work environment on varying levels of training outcomes. Human Resource Development Quarterly, 12, 5-23. doi:10.5465/ambpp.1997.4981395

Tziner, A., \& Falbe, C. M. (1993). Training-related variables, gender and training outcomes: A field investigation. International Journal of Psychology, 28, 203221. doi:10.1080/00207599308247185

Tziner, A., Fisher, M., Senior, T., \& Weisberg, J. (2007). Effects of trainee characteristics on training effectiveness. International Journal of Selection and Assessment, 15(2), 167-174. doi:10.1111/j.1468-2389.2007.00378.x

Tziner, A., Haccoun, R. R., \& Kadish, A. (1991). Personal and situational characteristics influencing the effectiveness of transfer of training improvement strategies. Journal of Occupational Psychology, 64, 167-177. doi:10.1111/j.20448325.1991.tb00551.x

Van den Bossche, P., Segers, M., \& Jansen, N. (2010). Transfer of training: The role of feedback in supportive social networks. International Journal of Training and Development, 14, 81-94. doi:10.1111/j.1468-2419.2010.00343.x

Van der Locht, M., Dam, K. Van, \& Chiaburu, D. S. (2013). Getting the most of management training: The role of identical elements for training transfer. Personnel Review, 42, 422-439. doi:10.1108/PR-05-2011-0072

Von Rosenbladt, B., \& Bilger, F. (2008). Weiterbildungsbeteiligung in DeutschlandEckdaten zum BSW-AES 2007 [Participation in further education in Germany- 
Key figures of the BSW-AES 2007]. Bonn, Germany: BMBF.

Velada, R., \& Caetano, A. (2007). Training transfer: The mediating role of perception of learning. Journal of European Industrial Training, 31, 283-296. doi:10.1108/03090590710746441

Velada, R., Caetano, A., Michel, J. W., Lyons, B. D., \& Kavanagh, M. J. (2007). The effects of training design, individual characteristics and work environment on transfer of training. International Journal of Training and Development, 11, 282-294. doi:10.1111/j.1468-2419.2007.00286.x

Vroom, V. H. (1964). Work and motivation. New York, NY: Wiley.

Watkins, K. E., \& Marsick, V. J. (1993). Sculpting the learning organization. San Francisco, CA: Jossey-Bass.

Webster, J., \& Martocchio, J. J. (1993). Turning work into play: Implications for microcomputer software training. Journal of Management, 19, 127-146. doi:10.1177/014920639301900109

Webster, J. \& Watson, R. (2002). Analyzing the Past to Prepare for the Future: Writing a Literature Review. Management Information Systems Quarterly 26(2), xiii-xxi. doi:10.2307/4132319

Weissbein, D. A., Huang, J. L., Ford, K. K., \& Schmidt, A. M. (2011). Influencing learning states to enhance trainee motivation and improve training transfer. Journal of Business and Psychology, 26, 423-435. doi:10.1007/s10869-0109198-x

Weisweiler, S. (2008). Der Einfluss von Individuum, Trainingsmaßnahme und Umfeld-eine Untersuchung zum Transferprozess in der Weiterbildung [The influence of the individual, the training measure, and the environment-An examination of the learning transfer process in further education] (Doctoral dissertation, Faculty of Psychology, Education and Sports Siences, University of Regensburg, Germany).

Weisweiler, S., Nikitopoulos, A., Netzel, J., \& Frey, D. (2013). Gaining insight to transfer of training through the lens of social psychology. Educational Research Review, 8, 14-27. doi:10.1016/j.edurev.2012.05.006

Werner, J. M., O'Leary-Kelly, A. M., Baldwin, T. T., \& Wexley, K. N. (1994). Augmenting behavior-modeling training: Testing the effects of pre- and posttraining interventions. Human Resource Development Quarterly, 5, 169-183. doi:10.1002/hrdq.3920050207

Zu Knyphausen-Aufseß, D., Smukalla, M., \& Abt, M. (2009). Towards a new training transfer portfolio: A review of training-related studies in the last decade. Zeitschrift fur Personalforschung, 23, 288-311. doi:10.1688/1862-0000_ZfP_2009_04_Knyphausen

Zurwehme, A. (2008). Management control in training institutions-Formation and results of an empirical study. Zeitschrift fur Planung \& Unternehmenssteuerung, 18, 445-469. doi:10.1007/s00187-007-0034-z 


\section{Bibliographical notes}

Dr. Cornelia Tonhäuser is Assistant Professor of Business Education with focus on Educational Management at the University of Göttingen, Germany. Her research areas are educational management, effectiveness and efficiency of further vocational training, professionalization of teachers and educational personnel and research on coaching topics.

Laura Büker (M.Ed.) is research assistant and doctoral student at the Chair of Business Education with focus on Educational Management at the University of Göttingen, Germany. Her research interests are efficacy of further vocational training and professionalization and professional development of teachers in business education. 